Chapter 5

\title{
Sleep and Chronic Obstructive Pulmonary Disease - the Role of Oxidative Stress in Overlap Syndrome
}

\author{
Radostina Vlaeva Cherneva, \\ Ognian Borisov Georgiev, \\ Daniela Stoichkova Petrova, Emil Ivanov Manov and \\ Julia Ivanova Petrova
}

Additional information is available at the end of the chapter

http://dx.doi.org/10.5772/57220

\section{Introduction}

Chronic obstructive pulmonary diseasese (COPD) is the fourth leading cause of mortality and its prevalence continues to increase. While the debilitating effects of COPD on daytime functioning are well known, COPD's effects on sleep have been less fully investigated. Sleep problems affect as many as $50 \%$ of patients with COPD. The mild hypoventilation that is physiologically observed during sleep is heightened in this patient group and is often accompanied by ventilation/perfusion mismatch. Significant hypoxemia ensues that is often accompanied by hypercapnia. These gas exchange abnormalities (particularly nocturnal oxygen desaturation, NOD) place COPD patients at increased risk of pulmonary hypertension, arrhythmias, and possibly cardiovascular death. Approximately 50\% of COPD patients with mild daytime hypoxaemia experience NOD which suggests that NOD may be a frequent occurrence with devastating consequences in individuals with COPD.

The increased prevalence of obesity worldwide is associated with a subsequent increase in the occurrence of sleep disordered breathing, particularly obstructive sleep apnea (OSA). The coexistence of OSA and COPD, known as the overlap syndrome, has been estimated to occur in $1 \%$ of the general population. The presence of one of the disorders, however, potentiates the occurrence of the other by more than $10 \%$. Overlap patients are a unique group of COPD patients who experience complex sleep disordered breathing, with nocturnal hypoxaemia and hypercapnia that is often disproportionately worse than their ventilatory impairments, pulmonary hypertension, and significant cardiovascular comorbidity. Evidence of systemic 
inflammation and oxidative stress in both COPD and OSA provides a common pathophysiologic link between these disorders which may predispose these individuals to increased cardiovascular morbidity and mortality. Further studies of the overlap syndrome are required to provide information on the additive and/or synergistic effects of these disorders at the molecular, physiological, and clinical level. Current, ongoing, long-term studies will provide information on the clinical consequences of the overlap syndrome, especially regarding cardiovascular mortality.

Despite the lack of understanding of the pathophysiologic processes mediating the development and effects of the overlap syndrome, treatment with continuous positive airway pressure (CPAP) reduces hypoxaemia, pulmonary and systemic hypertension, and improves survival. Furthermore, CPAP reduces exacerbations and lung decline in patients with the overlap syndrome.

Thus, a more aggressive approach in diagnosing OSA in COPD patients is strongly recommended. This chapter will acquaint you with the physiology of breathing in normal subjects and those with COPD, OSA, and overlap syndrome. We will review the effects of these disorders on sleep quality, gas exchange, and cardiovascular comorbidity. The current diagnostic and treatment options will be introduced. The role of oxidative stress in cardiovascular and metabolic comorbidity in OSA and overlap will also be discussed from our research perspective. The effect of bilevel positive pressure ventilation for one month on sleep quality, gas exchange, and ventilatory parameters, insulin resistance, and oxidative stress in overlap syndrome will also be reviewed.

\section{Sleep and ventilation}

\subsection{Sleep and ventilation in normal physiology}

Based upon the electroencephalographic characteristics, sleep can be divided into non-rapid eye movement sleep (NREM) and rapid eye movement sleep (REM) which have unique physiological characteristics. The four stages of NREM sleep are categorized by the presence of sleep spindles, K-complexes, and distinctive electro-occulogram and electromyogram findings. REM sleep is characterized by bursts of rapid eye movement, muscle atonia, and shallow and irregular breathing. It is subdivided into two periods: tonic and phasic. Four to five cycles of recurring NREM and REM episodes occur throughout the night. The duration of REM sleep increases during the night, being longest in the last part of nocturnal sleep. Sleep profoundly affects breathing by altering respiratory drive, minute ventilation, and ventilation/ perfusion matching.

\subsubsection{Respiratory drive}

The physiological mechanisms of breathing during sleep are similar to those in wakefulness except for the fact that feedback mechanisms are blunted. This dampening effect is mostly attributed to the slight decrease in the metabolic rate during sleep which attenuates the 
response to mechanical, cortical, and metabolic stimuli [1,2]. The ventilatory and arousal responses to hypercapnia are much more robust than for hypoxia, with only slight changes in $\mathrm{PaCO} 2$ causing recognizable alterations of minute ventilation [3]. However, under normal conditions in sleep and especially during periods of REM, the responses to hypoxaemia and hypercapnia are blunted in comparison to wakefulness. The diminished ventilatory responses to hypercapnia and hypoxia are more profound during REM compared with NREM sleep [1, 4]. These attenuated feedback mechanisms stress the respiratory system which in individuals with COPD is already deranged and dysfunctional. The combinations of sleep disordered breathing, impaired respiratory function, and dampened feedback interactions may cause significant reductions in minute ventilation and precipitate respiratory failure

\subsubsection{Minute ventilation}

Compared to wakefulness, minute ventilation decreases during NREM sleep and declines even further during REM sleep when minute ventilation may be $15 \%$ less than occurs during wakefulness. The minute ventilation decrease is caused by a reduction in tidal volume due to muscle atonia and cephaloid displacement of the diaphragm that is not fully compensated by an increase in respiratory frequency [5]. The consequence is sleep related hypoventilation which causes a significant reduction $(2-8 \mathrm{mmHg})$ in the partial pressure of oxygen in arterial blood $\left(\mathrm{PaO}_{2}\right)$ and an increase in the partial pressure of carbon dioxide (3-10mmHg) in arterial blood $\left(\mathrm{PaCO}_{2}\right)$ [6]. The decreased muscle tone during sleep increases respiratory resistance and the inability to compensate for these changes probably contributes to attenuated physiologic responses [7]. During NREM sleep, the phasic electromyographic activity of the genioglossus and geniohyoid muscles is well-maintained [8], but tonic activity of upper airway dilator muscles decreases [9]. During REM sleep, breathing is shallow and irregular and upper airway resistance increases due to full skeletal-muscle atonia [10].

\subsubsection{Ventilation-perfusion mismatch}

During NREM sleep, lung volume decreases leading to a reduction in the functional residual capacity (FRC) [11]. Reduction in lung compliance and reduced respiratory muscle tone, have been suggested as potential causal factors in the reduction in FRC [12]. It has been hypothesized that reduced FRC during sleep may contribute to the airway closure, causing ventilationperfusion mismatch and, thus, contributing to the small changes in arterial oxygen saturation especially during REM sleep [13].

\subsection{Sleep and ventilation in COPD patients}

The control of breathing in patients with COPD follows the same basic principles as in normal subjects. The lower baseline oxygenation and abnormal respiratory mechanics in patients with COPD become clinically important when combined with the normal physiologic alterations in ventilatory control and respiratory muscle tone that occur during sleep. In COPD patients, the more profound decrease in oxygen saturation during sleep is mainly attributed to the lower $\mathrm{PaO}_{2}$ during wakefulness. This $\mathrm{PaO}_{2}$ level is on a steeper section of the $\mathrm{O}_{2}$ dissociation curve; thus, a slight decline in oxygenation leads to a more profound reduction in oxygen saturation. 
Thus, nocturnal oxygen desaturation (NOD) is the most significant sleep abnormality associated with COPD $[14,15]$. Even without any upper-airway contribution, various studies have reported that $27-70 \%$ of patients with COPD with awake oxygen saturation levels of $90-95 \%$ can experience substantial desaturation at night, particularly during REM sleep [16-18].

\subsubsection{Definition of NOD}

The definition of NOD varies depending on various studies. At least three different definitions have been used: 1) Mean nocturnal oxygen saturation $\left(\mathrm{SaO}_{2}\right)<90 \% ; 2$.) $\mathrm{SaO}_{2}<90 \%$ for more than $30 \%$ of recording time (total time in bed); 3) $\mathrm{SaO}_{2}<90 \%$ for more than 5 minutes of recording time with a nadir $<=85 \%$. Most studies use either definition 2 or 3 [19]. Similarly, the definition for the amount of desaturation dip is not universal. Wynee and colleagues [20] defined a desaturation dip by a fall in $\mathrm{SaO}_{2}$ by more than $4 \%$ from baseline during quiet breathing just before the episode of hypoxemia. Flenley's group [6,21] defined a dip as a $10 \%$ or greater drop in $\mathrm{SaO}_{2}$.

The nocturnal oxygen desaturation in COPD patients presents specific characteristics. It takes place at the end of the night during REM sleep [22] and may be variable from one night to the other, especially in patients with moderate-to-severe COPD [23]. The desaturations are significantly related to daytime hypoxaemia and hypercapnia [24]-the more pronounced daytime hypoxaemia and hypercapnia, the more severe nocturnal desaturation [25].

\subsubsection{Mechanisms of NOD}

Flenley [25] identified three mechanisms that might contribute to nocturnal oxygen desaturation: 1) alveolar hypoventilation; 2) decreased ventilation/perfusion matching; 3) decreased end-expiratory lung volume. Subsequent research confirmed much of his hypothesis. The description of sleep disordered breathing, particularly, obstructive sleep apnea, led to the introduction of the overlap syndrome in 1985 as an independent phenomenon in COPD patients [25].

\subsubsection{Alveolar Hypoventilation}

Alveolar hypoventilation plays a significant role in NOD, especially during REM sleep. The exact mechanism causing alveolar hypoventilation in COPD patients is arguable. This may be due to the type of measurements performed, the stage of sleep (REM vs. NREM), and the status of subjects-normocapnic or hypercapnic COPD patients. Becker et al [5] observed a drop in minute ventilation of $16 \%$ and $32 \%$ during non-REM and REM sleep, respectively. This reduction was predominantly due to a decrease in tidal volume measured by a pneumotachograph. The greater drop in minute ventilation in subjects with COPD may reflect increased dependence on accessory muscles that become hypotonic during sleep, particularly during REM sleep, as well as the presence of blunted chemical respiratory drive. Ballard and coworkers [10] showed a decrease in minute ventilation in COPD patients which was associated with an increase in upper airway resistance as well as a decrease in neuromuscular output to the respiratory muscles rather than a decrease in lung volumes. O'Donoghue et al [26] noted 
a decline in minute ventilation in NREM sleep in hypercapnic COPD patients due to a decrease in tidal volume and an increase in upper airway resistance. Although the exact mechanism is unknown, current evidence suggests that alveolar hypoventilation during sleep contributes to NOD in COPD patients.

\subsubsection{Ventilation-perfusion $(V / Q)$ mismatch}

V/Q mismatch has not been directly measured during sleep. However, for a mild and similar increase in $\mathrm{PaCO}_{2}$ (and thereby alveolar hypoventilation), some COPD patients had more significant decreases in nocturnal $\mathrm{PaO}_{2}$ than others, suggesting a role for $\mathrm{V} / \mathrm{Q}$ mismatch as a mechanism for NOD [24]. This may be due to reduced lung volumes (particularly functional residual capacity-FRC) caused by declines in respiratory muscle tone leading to atelectasis at the lung bases. It is likely that in COPD patients, especially during REM, the ventilation/ perfusion mismatch may be due to the dissociation between intercostal and diaphragmatic activity on one hand [22] and the cephaloid displacement of the diaphragm and decreased FRC on the other [27].

\subsubsection{Impact of oxyhemoglobin dissociation curve}

Hypoxaemic patients at baseline are more likely to drop their $\mathrm{SaO}_{2}$ with hypoventilation during sleep, compared to normoxic patients due to the effect of the oxyhemoglobin dissociation curve [22]. Mild decreases in oxygenation change the location on the oxygen-hemoglobin dissociation curve from the plateau to the edge of the slope where a slight decrease in oxygenation will cause a profound decline in oxygen saturation. This effect is not an independent mechanism but contributes to the NOD in collaboration with other factors.

\subsubsection{Obstructive sleep apnea (Overlap syndrome)}

Patients with coexisting obstructive sleep apnea (overlap syndrome) may be hypoxaemic at the commencement of an apnea and thus are more likely to desaturate compared to patients with only OSA who may be able to recover to a normal $\mathrm{SaO}_{2}$ after the apneic episode. Overlap syndrome and its mechanisms and consequences will be discussed in detail.

\subsubsection{Consequences of NOD}

Potential consequences of NOD are mainly related to cardiovascular mortality and morbidity and affect pulmonary haemodynamics mainly.

\subsubsection{Pulmonary hypertension}

Alveolar hypoxemia is the major mechanism that triggers pulmonary arterial vasoconstriction and leads to pulmonary hypertension [28]. In a study of 12 patients with COPD, an acute increase in pulmonary artery pressure was noted in all sleep stages, most significantly in REM. The increase corresponded much more to the decrease in $\mathrm{PaO}_{2}$ compared to the rise in $\mathrm{PaCO}_{2}$ [29]. Although highly persuasive, there is still not enough evidence for a causational 
link between sleep oxygen desaturation episodes and the development of pulmonary hypertension in COPD patients.

Pulmonary haemodynamic studies during sleep in COPD patients have been scarce as the invasive nature of their investigation is not compatible with normal sleep [30]. Moreover almost all of them are in severe COPD patients with daytime hypoxaemia, marked nocturnal hypoxaemia, and daytime pulmonary hypertension (pulmonary artery pressure (PAP) $>20$ $\mathrm{mm} \mathrm{Hg}$ ) [31-33]. Nocturnal elevation of PAP appears to correlate with NOD in this patient population [33]. Whether this correlation stays true in patients with mild and moderate COPD with less diurnal hypoxaemia is elusive.

In patients with mild and moderate COPD, studies on the relationship between pulmonary hypertension and NOD are not conclusive and their interpretation depends on the type of definition used for NOD, as well as the amount of decrease in $\mathrm{PaO}_{2}$ [34,35,36]. Fletcher et al [34] studied 36 COPD patients who had daytime $\mathrm{PaO}_{2}>60 \mathrm{~mm} \mathrm{Hg}$ and NOD during REM sleep (a drop in $\mathrm{SaO}_{2}<90 \%$ for 5 minutes or more and a nadir of at least $85 \%$ ). They measured an increase in systolic and mean pulmonary artery pressures, as well as pulmonary vascular resistance. In forty COPD patients with a daytime $\mathrm{PaO}_{2}$ of $60-70 \mathrm{~mm} \mathrm{Hg}$, Levi-Valensi et al [35] detected higher mean pulmonary artery pressures in those individuals with NOD compared with those who did not have NOD (defined as $\mathrm{SaO}_{2}<90 \%$ for $>30 \%$ of total time in bed (TIB)). In a larger group of $66 \mathrm{COPD}$ patients with a daytime $\mathrm{PaO}_{2}>60 \mathrm{~mm} \mathrm{Hg}$, Chaouat et al [16] found no difference in the mean pulmonary artery pressure measured by right heart catheterization. NOD was defined by the same criteria used by Levi-Valensi.

In conclusion, acute nocturnal oxygen desaturation is associated with increases in both systemic and pulmonary blood pressures [34]. It is very likely that the repetitive, transient nocturnal oxygen desaturations that appear in some COPD patients can cause pulmonary hypertension [37]. Which patients are more likely to be affected by NOD and what clinical factors predict the hemodynamic effects of NOD are unknown. It is, however, generally assumed that patients with COPD and daytime normoxia who have only nocturnal oxygen desaturation generally do not develop substantial pulmonary hypertension. This assumption is supported by the lack of efficacy of nocturnal supplemental oxygen in treatment trials in this patient population [38]

\subsubsection{Cardiac arrhythmias}

Various arrhythmias are reported during episodes of nocturnal desaturation [4]. These consequences might explain why nocturnal oxygen desaturation is a marker of increased mortality and why COPD patients are reported to die more frequently at night than expected [39]. Though some studies have shown increased frequency of premature supraventricular and ventricular contractions (PVC) during sleep in COPD patients, overall there appears to be no correlation between PVC's and nocturnal $\mathrm{SaO}_{2}[40,41]$. 


\subsubsection{Polycythemia}

Daytime hypoxaemia in COPD patients is a well known cause of polycythemia. However, NOD without daytime hypoxaemia has not been associated with polycythemia [35,42]. In addition, there is no clear evidence that erythropoetin is increased in COPD patients with primary NOD [43].

\subsubsection{Sleep quality}

NOD can also affect sleep quality. Arousals may be related to episodes of desaturation [44] and, consistent with this observation, some (but not all) studies have shown that supplemental oxygen improves sleep quality [6].

\subsubsection{Mortality}

While some COPD patients die due to respiratory failure, they more frequently die from cardiovascular disease or malignancy [45]. There is some evidence that these deaths occur predominantly at night. McNicholas reported that patients admitted to the hospital with chronic bronchitis or emphysema were more likely to die at night than other hospital patients. Deaths occurred more frequently among so called "blue-bloaters" [39]. Although these data relate to patients with daytime hypoxaemia, the effect of NOD on survival of COPD patients without significant daytime hypoxemia is not well established. Fletcher et al [34] performed a retrospective study in 169 COPD patients without daytime hypoxemia. NOD was definedeither as a drop in $\mathrm{SaO}_{2}$ below $90 \%$ for 5 or more minutes reaching a nadir of $85 \%$ or as $\mathrm{SaO}_{2}<90 \%$ for $>30 \%$ of TIB. Although patients with NOD had improved survival compared to the non-NOD group, correcting NOD has not shown to improve survival. In 97 COPD patients, Connaughton et al [46] found no survival advantage when they followed them for a median of 70 months, performing nocturnal SaO2 measurement.

Comorbid OSA was recently reported to increase mortality in patients with COPD. Marin et al, published outcome data on patients with COPD and patients with the overlap syndrome, both with and without CPAP treatment [47]. Subjects were initially screened because of a clinical suspicion of sleep-disordered breathing. Then, a diagnostic polysomnogram and spirometry were performed. After a median follow-up of over 9 years, all-cause mortality was higher in the untreated (without CPAP) overlap group (42.2\%) than in the COPD-only group (24.2\%). Even after adjustment for COPD severity, comorbid OSA remained a risk factor for death. In this study, death in the untreated overlap group was most commonly attributed to cardiovascular disease. In the overlap group, OSA contributed to an increased incidence of COPD exacerbations, which may accelerate lung-function decline and, hence, augment mortality $[48,49]$

The exact mechanism(s) for the increased mortality risk in overlap syndrome is not established. Increased risk of death may be due to more prolonged hypoxia. Nighttime hypercapnia may also be important. The systemic consequences of both COPD and OSA should also be considered. They both cause inflammation and oxidative stress. Whether these mechanisms are additive or synergistic is, however, unknown. 


\section{Sleep quality in copd}

\subsection{Characteristics of sleep disturbances}

Insomnia and other sleep problems are increased in patients with COPD [44]. Elderly COPD patients experience more morning tiredness and early awakenings [50]. The most commonly reported sleep disturbances are insomnia, poor sleep maintenance, early morning awakenings and headaches, and daytime sleepiness. These symptoms occur in approximately $30-70 \%$ of patients with COPD [44, 50,52]. When surveyed for a broad range of symptoms, "sleep difficulties" were mentioned as occurring "almost always" or "always" in 43\% of subjects with either chronic bronchitis or emphysema and were the third (after dyspnea and fatigue) most common complaint [53]. The sleep architecture of individuals with COPD is notable for many arousals. These arousals were attributed not just to the diagnosis of COPD, but largely due to the presence of related symptoms-cough, sputum production, or wheezing. These symptoms correlated most with difficulty falling or staying asleep [53]. Many COPD patients report use of hypnotics (28\% compared to controls- $10 \%$ ) to combat sleep disturbances [44].

Subjective complaints of sleep disturbances appear to be associated with the presence of objective evidence for disturbed sleep quality in patients with COPD (predominantly in small cohorts of patients with severe COPD) as documented by overnight polysomnograms (PSGs). These findings include increased sleep latency, decreased total sleep time, decreased sleep efficiency, increased nocturnal arousals, decreased slow-wave sleep, and decreased REM sleep $[6,20,44,54]$. Cormick et al found significant agreement between subjective complaints of initiating and maintaining sleep and objective findings of poor sleep quality as shown by a decreased total sleep time of 208 minutes and increased arousal index [44].

Sleep disturbances may not be as pervasive in patients with mild/moderate COPD. The Sleep Heart Health Study (SHHS) did not show altered sleep quality in mild COPD patients $\left(\mathrm{FEV}_{1} /\right.$ FVC $63.81 \pm 6.56 \%$ ) [55]. Sanders et al observed that COPD only patients had minimally perturbed sleep and found no correlation between the decline in $\mathrm{FEV}_{1}$ and sleep architecture. In a community-based study, Redline et al [56] showed that sleep structure variables did not change in subjects with a history of lung disease. In addition, they found that sleep stage distributions varied in accordance with AHI level.

\subsubsection{Mechanisms of sleep disturbances in COPD patients}

Various reasons for sleep disturbances in COPD patients exist. The most common are cough, dyspnea, nocturnal oxygen desaturation (NOD), hypercapnia, degree of airway obstruction (measured by $\mathrm{FEV}_{1}$ ), and medication side effects [6,20,44,54,57]. Although SHHS suggests a lesser degree of effect on sleep quality in patients with milder COPD, no clear relationship between sleep quality measures and $\mathrm{FEV}_{1}$ is established [50]. Poor-quality of sleep may be associated with hypoxaemia and increased superficial sleep [58]. 


\subsubsection{Consequences of sleep disturbances}

The poor sleep quality in COPD patients may lead to decreased daytime functioning due to excessive daytime sleepiness, altered neurocognition, and psychomotor vigilance. There are no studies that address whether neurocognition or psychomotor vigilance are affected in COPD patients. COPD patients often complain of daytime sleepiness. However Orr et al [59] found no objective evidence for daytime sleepiness based on multiple sleep latency testing in 14 severe COPD patients who had poor sleep quality based upon decreased total sleep time and increased arousal index.

\section{Predictors of nod in copd patients}

Approximately $27-70 \%$ of patients with COPD with awake $\mathrm{SaO}_{2}, 90-95 \%$, can experience substantial desaturation at night, especially during REM sleep [20,24]. The high prevalence of NOD and its consequences on haemodynamics are a challenge for many researchers who have attempted to determine daytime physiological parameters that might help in predicting NOD in COPD. Although NOD is more pronounced in COPD patients with daytime hypoxaemia, it is established that an additional quarter of patients with adequate oxygenation during wakefulness can experience NOD [20,24].

\subsection{Severe COPD}

In severe COPD, the 'blue bloater' rather than the 'pink puffer' phenotype is more likely to have NOD [60]. Various studies showed that the blue bloaters had lower baseline oxygen saturations, more episodes of NOD, larger falls in NOD, and spent more time at low levels of oxygen saturation while asleep, than the pink puffers [6,20,21]. A significant relationship between waking values of low $\mathrm{PaO}_{2}$ and high $\mathrm{PaCO}_{2}$ with $\mathrm{NOD}$ was also established $[42,44,61]$. Moreover, although there was a good correlation between mean sleep $\mathrm{SaO}_{2}$ and mean exercise $\mathrm{SaO}_{2}$, the awake $\mathrm{PaO}_{2}$ appeared to be a better predictor for NOD than exercise desaturation [24]. The desaturation nadir was lower during sleep than during exercise, with oxygen saturation falling an average of $6 \pm 4 \%$ during peak exercise and $13 \pm 9 \%$ during sleep [62]. Pulmonary function testing correlated poorly with nocturnal hypoxaemia[55].

In summary, most evidence suggests that awake oxygen saturation is a better predictor for NOD in severe COPD patients than PFT parameters or exercise desaturations [24,63]. Increased daytime $\mathrm{PaCO} 2$ also carries an increased risk for NOD [55].

\subsection{Mild and moderate COPD}

The clinical approach to NOD detection in COPD is more difficult in patients with mild/ moderate COPD (GOLD I-II) and mild daytime hypoxaemia. Approximately one quarter of these individuals have NOD, which is independent of the co-existence of OSA [42]. Current guidelines for evaluation of nocturnal oxyhemoglobin saturation in COPD patients without significant daytime hypoxaemia, however, are restrictive. Measuring nocturnal oxyhemoglo- 
bin saturation in COPD patients who have daytime $\mathrm{PaO} 2-55-59 \mathrm{~mm} \mathrm{Hg}$ is not recommended [64]. Polysomnography should be performed in COPD patients whose symptoms are suggestive of coexistent OSA.. Other high risk groups include is COPD patients with daytime hypercapnia and only moderately reduced $\mathrm{FEV}_{1}$; obese snorers, those who develop headache after nocturnal oxygen therapy, and patients with mild hypoxaemia and unexplained polycythemia, pulmonary hypertension, and cor pulmonale [64]. Witnessed apneas while asleep and daytime sleepiness are also highly suspective of OSA [65]. However, the presence of concomitant OSA is often difficult to predict from daytime symptoms in patients with mild/ moderate COPD. They do not have daytime hypercapnia, headache, or daytime sleepiness. Classic sleep complaints and daytime sleepiness are not common. COPD alone, when moderate, does not disturb sleep quality, and OSA may not always present with sleep complaints. So if sleep complaints are the trigger for polysomnography in mild/moderate COPD, a large number of patients will not be tested.

\section{Diagnostic approaches to detecting nod in copd patients}

Nocturnal oximetry alone is probably not helpful diagnostically in COPD patients, as nocturnal oxygen desaturation may reflect only COPD or some combination of COPD and OSA, and treatment will differ (see below). Definitions of nocturnal oxygen desaturation differ, and physician decision and management based on nocturnal oximetry results differ greatly. Finally, there is little evidence that correction of nocturnal hypoxemia in COPD with only nocturnal desaturation improves outcomes [38].

Epidemiological data suggest that nocturnal oxyhemoglobin desaturation either related or unrelated to OSA is present in at least $50 \%$ of COPD patients without significant daytime hypoxaemia. Considering that approximately half of these patient have coexistent OSA, clinicians should establish the diagnosis of OSA in these patients. Nocturnal oxymetry should be performed in severe COPD, in mild and moderate COPD patients with the clinical characteristics listed in table 1. Patients with COPD who are diagnosed with nocturnal hypoxaemia by nocturnal oxymetry should undergo attended nocturnal polysomnography to exclude coexistent OSA.

\begin{tabular}{ll}
\hline Mild COPD & Severe COPD \\
\hline Daytime hypoxemia disproportionate to $\mathrm{FEV}_{1}$ & Blue boaters \\
\hline Daytime Hypercapnia disproportionate to $\mathrm{FEV}_{1}$ & Daytime hypoxemia $\mathrm{PaO}_{2}<55 \mathrm{mmHg}$ \\
\hline Pulmonary hypertension disproportionate to $\mathrm{FEV}_{1}$ & \\
\hline FEV $1<65 \%$ & \\
\hline Obese snorers & \\
\hline Sleep complaints & \\
\hline Witnessed apneas, hypopneas
\end{tabular}

Table 1. Indications for performing a nocturnal oxymetry in mild/severe COPD 


\section{Osa as a mechanism for nod}

Obstructive sleep apnea (OSA) is an independent phenomenon, leading to sleep-disordered breathing that is characterized by a cessation (apnea) or limitation (hypopnea) of airflow accompanied by a desaturation (Figure 1). OSA is diagnosed when more than 5 apneas and hypopneas occur per hour of sleep and are associated with excessive daytime sleepiness. OSA and COPD are two common respiratory diseases whose combination was first noted by Flenley [25] and is now recognized as the classic overlap syndrome (Figure 2). Both OSA and COPD have systemic inflammatory consequences that are responsible for increased cardiovascular morbidity and mortality. Moreover, until recently, OSA itself was categorized as an inflammatory consequence of COPD [66]. For this, as well as many other reasons, OSA and the overlap syndrome will be discussed separately in this chapter. Although they share common manifestations, COPD and OSA are united in the overlap syndrome, presenting a unique combination of upper and lower airway resistance and a blunted respiratory drive. In overlap patients, these disorders have more than an additive or synergistic effect, but rather present as an independent sleep-related breathing abnormality.

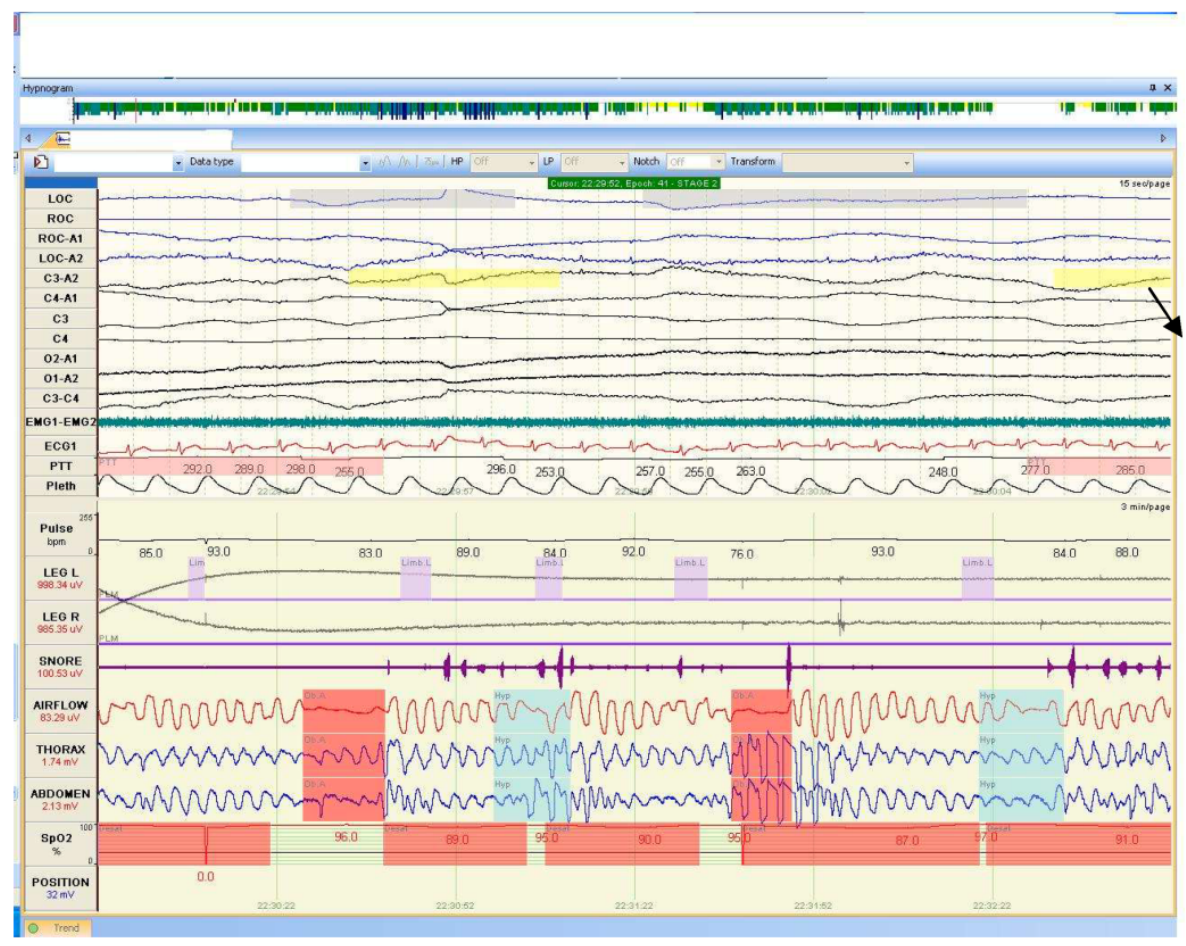

Figure 1. Polysomnogram of a patient with OSA only (note the desaturations highlighted by the circles and arrows) 


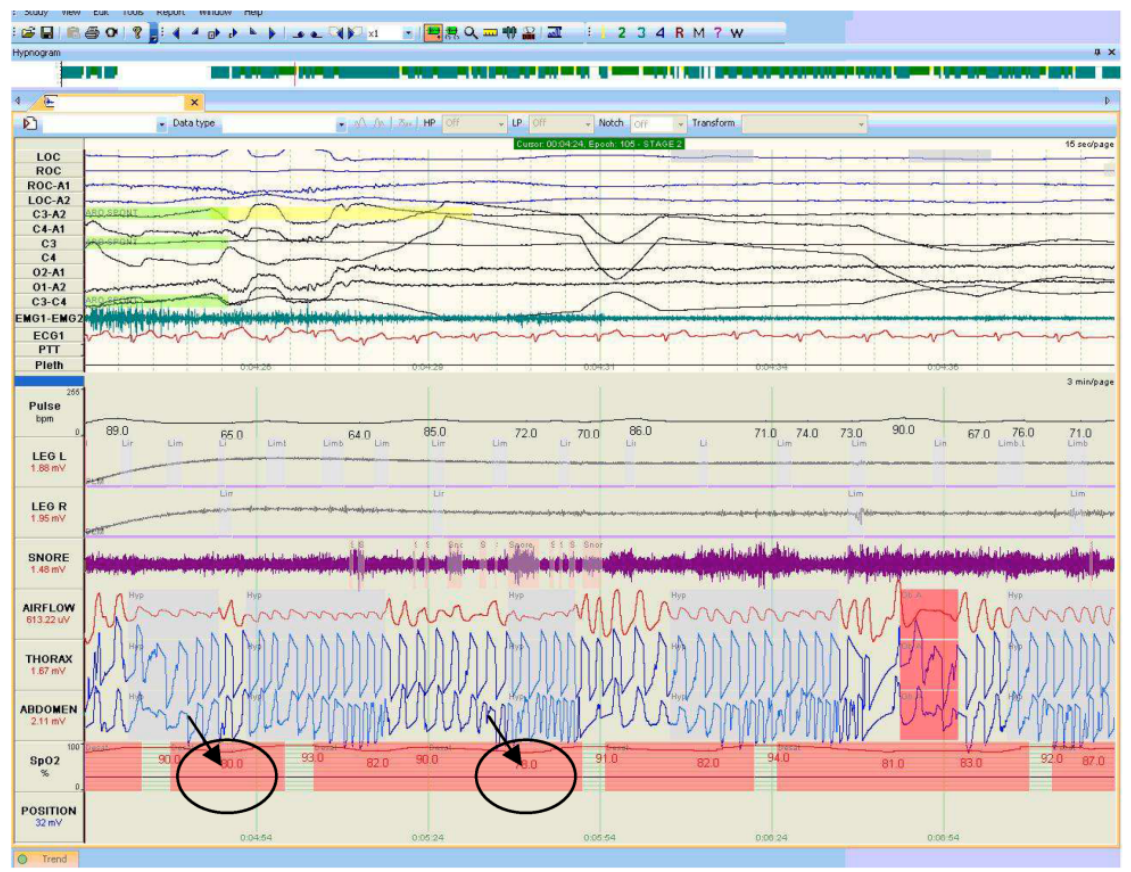

Figure 2. Polysomnogram of a patient with overlap syndrome (the desaturation is more severe; desaturations are highlighted by the circles and arrows)

\subsection{Sleep and respiration in OSA}

During apneas, the collapsed pharynx impedes airflow in spite of the respiratory effort. The obstruction leads to progressive asphyxia, which additionally stimulates breathing against the collapsed airway and usually continues until the person awakens [67]. Various factors-upper airway anatomy, central respiratory control mechanisms etc., contribute to the development of the clinical syndrome of OSA. The primary defect might be an anatomically small or collapsible pharyngeal airway, in combination with sleep-induced upper airway muscle atonia $[68,69]$. Instability of ventilatory control $[70,71]$ or inefficiency of the central respiratory drive that modulates upper airway resistance in OSA may be other factors responsible for this disorder [72]. Abnormal hypoxic and hypercapnic respiratory response has also been reported in hypercapnic OSA patients [73,74]. The role of reduced chemical feedback is, however, still under debate. It is not clear whether the abnormal hypoxic and/or hypercapnic respiratory response is secondary to sleep apnea or is an inherited abnormality in ventilatory control [75, 76]. The improvement in the ventilatory feedback to $\mathrm{CO}_{2}$ in hypercapnic OSA patients after $\mathrm{CPAP}$ therapy suggests that this dysregulation is acquired and not genetic $[77,78]$. 


\subsection{OSA and COPD - predisposing factors and prevalence}

Whether any pathophysiological link exists between OSA and COPD is still unknown, but they share common risk factors and pathophysiological processes that contribute to the genesis and exacerbation of each other. The relationship between COPD and OSA may be influenced by smoking and BMI. Neck obesity contributes to upper airway narrowing while truncal obesity promotes ventilatory disturbances by reduced chest wall compliance and muscle strength. Visceral obesity is responsible for reduced residual capacity and contributes to ventilation/perfusion mismatch. BMI may be lower in some patients with COPD, especially those with advanced disease and may be protective against OSA [27,65].

Smoking is another risk factor for COPD that, in addition, predisposes to sleep apnea. It increases airway resistance due to local inflammation and edema. Besides BMI and smoking, OSA and COPD may by themselves contribute to the onset of each other.

Redolfi et al [79] demonstrated that, even in healthy subjects, there is an overnight fluid shift from the legs that increases neck circumference. In COPD patients with cor pulmonale and peripheral edema, rostral fluid shifts that occur during supine positioning may contribute to pharyngeal narrowing and favour the onset of obstructive apneas/hypopneas. The corticosteroid induced myopathy or the cachexia that occurs in advanced COPD stages may be the reason for blunted inspiratory force. Local pharyngeal muscle edema associated with steroid inhalations might contribute to upper airways narrowing, thus facilitating sleep/disordered breathing [80]. Increased end-expiratory lung volume within an individual improves upperairway mechanics, probably via tracheal traction. In emphysematous COPD patients, although end-expiratory lung volume may be elevated, the loss of lung recoil may not be protective for upper-airway mechanics. It is assumed that the decreased tethering of airways by destruction of parenchyma may actually produce a more collapsible upper airway [81]. Repetitive upperairway collapse increases lower-airway resistance in an animal model suggesting that OSA might itself promote COPD [82]. Finally, in order to lose or maintain weight, or to fight excessive daytime sleepiness, patients with OSA might smoke more frequently than those without it [83].

\subsection{Epidemiology}

Initial studies may have overestimated the prevalence of overlap syndrome [84]. Patients with obstructive lung disease, referred mostly for evaluation of excessive daytime sleepiness, were determined to frequently have OSA as well [85]. In early studies, a high prevalence of OSAS was found in individuals with COPD. Guilleminault et al [86] studied 26 COPD patients while sleeping and found that $92 \%$ of all abnormal respiratory events during sleep contained an obstructive component. Conversely, patients with known OSA were evaluated with spirometry and $11 \%$ were found to have an $\mathrm{FEV}_{1} / \mathrm{FVC}<0.601$ [87]. Another study found the prevalence of the overlap syndrome to be $29 \%$, although the data were gathered in a retrospective chart study of patients who had been refered for polysomnography and who also had an interpretable pulmonary function test [88]. The seemingly very high prevalence prompted speculation that OSA and COPD were linked by a common mechanism or common pathophysiology. 
Recently, however, data from the Sleep Heart Health Study, a prospective multicenter cohort study showed that overlap syndrome has a prevalence of $14 \%$ among patients with mild COPD which is not different from those without COPD (18.6\%) [55]. The presence of airway obstruction did not seem to affect the respiratory disturbance index. The Multinational Monitoring of Trends and Determinants in Cardiovascular Disease [MONICA-II]) also found no increased risk between the two disorders [89]. The major limitation of these studies, however, is that most subjects had very mild airway obstruction on spirometry.

Although there may be no increased association between relatively mild COPD and OSA because of the rising prevalence of these diseases, a patient with one of the disorders will often have the other disease. For example, in the Sleep Heart Health Study and the MONICA-II study, GOLD stage II COPD was found in $19 \%$ and $11 \%$ of the subjects with OSA, respectively. Sleep-disordered breathing was seen in $14 \%$ of subjects in the Sleep Heart Health Study (respiratory disturbance index $>15$ events/h) and $11 \%$ of subjects (AHI $>5$ events/h and excessive daytime sleepiness) in the MONICA-II cohort [55,89]. A patient with one of the disorders has a greater than $10 \%$ chance of also having the other. Thus, when seeing a patient with either OSA or COPD, it is reasonable to screen for the other disorder.

Our experience generally confirms the findings from the SHHS and MONICA II cohorts. From January-December, 2011, we performed a prospective study of patients with complaints of daytime sleepiness, witnessed apneas and/or hyponeas who were referred to the Sleep Lab, Division of Pulmonology, Clinic of Internal Medicine, University Hospital Alexandrovska, Sofia. Only patients who signed informed consent participated in the study. The aim of the study was to compare the anthropometric, metabolic, cardiovascular, and respiratory characteristics of patients with OSA and overlap syndrome. Gas exchange and ventilatory parameters were also compared. The level of oxidative stress, measured by the urinary concentration of 8 -isoprostanes was of special interest. A correlation between oxidative stress and cardiovascular and metabolic comorbidity was investigated. Patients were followed for a month after the initiation of bilevel positive pressure ventilation (BiPAP). The effect of this treatment modality on the level of oxidative stress, gas exchange, and ventilatory parameters measured by pulmonary function testing was studied.

Patients who agreed to participate in the study underwent a full polysomnography (Compumedics, Australia). Continuous recordings were taken with electrode positions C3/A2-C4/A1$\mathrm{Cz} / 01$ of the international 10-20 Electrode Placement System; eye movements, chin electromyogram, and ECG modified V2 lead were also recorded. Sleep was scored manually according to standard criteria. Airflow was measured using nasal pressure associated with the sum of buccal and nasal thermistor signals. Respiratory efforts were monitored with abdominal and thoracic bands. Arterial oxygen saturation $\left(\mathrm{SpO}_{2}\right)$ was measured using a pulse oximeter. An apnoea was defined as a complete cessation of airflow for $>10 \mathrm{~s}$, and a hypopnoea as a $>50 \%$ reduction in the nasal pressure signal or a $30-50 \%$ decrease associated with either oxygen desaturation of $>3 \%$ or an arousal (defined according to the Chicago report or by autonomic activations on pulse transit time), lasting for at least $10 \mathrm{~s}$. Apnoeas were classified as obstructive, central, or mixed according to the presence or absence of respiratory efforts. The diagnosis of OSA was established if the AHI was $>5$ events/h [90]. 
For the period of the study, 265 patients with newly diagnosed OSA signed an informed consent to participate in the study. COPD was determined in accordance with the GOLD criteria, $2011-\mathrm{FEV}_{1} / \mathrm{FVC}<70 \%$ after administration of a bronchodilator [91]. 26 (9.8\%) patients (23 men; 3 women) were diagnosed with overlap syndrome. All patients had stage II COPD $\left(80 \%>\mathrm{FEV}_{1}<50 \%\right)$. These findings corroborate the results of larger epidemiological studies measuring the prevalence of overlap syndrome in patients with moderate COPD.

\subsection{Overlap syndrome and physiological consequences}

\subsubsection{Gas exchange}

The majority of patients with OSAS are eucapnic during wakefulness. Daytime hypercapnia is usually associated with mechanical impairment of the respiratory system related to obesity and/or COPD [92,93]. It is also associated with the severity of OSA, higher BMI levels, or degree of restrictive chest wall mechanics. Hypoxaemia is also described in OSA. It is closely related to apneas and hypopneas and is a result of alveolar hypoventilation.

In overlap syndrome, however, there is a predisposition to daytime hypercapnia and hypoxaemia that is independent of lung function [16]. Nocturnal desaturation severity varies within the wide spectrum of sleep-disordered breathing and the severity of COPD. In overlap patients, the nocturnal desaturation is greater and lasts longer than in patients with either OSAS or COPD. OSA seems to be an important cause of hypercapnia and hypoxemia in some COPD patients that is disproportionate to their lung function impairment. Chan et al [94] showed that hypercapnic COPD patients have higher BMI and smaller airway cross sectional areas when compared with lung function matched eucapnic controls. Furthermore, it is known that overlap patients have more nocturnal desaturation events than patients with either COPD or OSA alone [55]. Sanders and colleagues examined the degree to which COPD and OSAS independently and jointly contribute to desaturations during sleep [55]. After adjusting for confounding factors, the odds ratio for nocturnal oxyhemoglobin desaturation $\left(\mathrm{SpO}_{2}<85 \%\right.$ for more than $20 \%$ of total sleep time) was 20 times greater in OSA and 30 times greater in overlap syndrome. Bednarek et al [89] demonstrated that patients with overlap syndrome had lower mean arterial blood oxygen saturations and spent more time in desaturation than the OSAS group when polysomnography variables were compared.

These observations are confirmed by our own investigations. We compared overlap syndrome patients to patients with OSA alone. Patients with OSA had a moderate degree of sleep disordered breathing with an average AHI $-24.11 \pm 5.34$ events/h. They were compared to AHI and age matched patients with overlap syndrome. The overlap patients had an average AHI - 28.14 \pm 5.47 events/h. 21(80\%) patients had moderate OSA (AHI 15-30 events/h); 5 (20\%) had mild OSA (AHI 5-15 events/h). The average desaturation in overlap and OSA was $12.3 \%$ vs $6.9 \%$ ( $\mathrm{p}=0.037$ ), respectively. The proportion of sleep time with $\mathrm{SaO}_{2}<90 \%$ in the overlap group was greater, $57.21 \%$, in comparison with the OSA only group, $34.8 \%$, p=0.042.

The nighttime respiratory disturbances reflected the daytime gas exchange parameters. In overlap patients, the average daytime $\mathrm{PaO}_{2} 2$ was $61.67 \pm 5.78 \mathrm{mmHg}$ vs $75.59 \pm 8.43 \mathrm{mmHg}$ in OSA. The prevalence of hypercapnic patients was greater in the overlap (19.2\%) with an 
average daytime $\mathrm{PaCO}_{2}$ in the group $-52.14 \pm 11.39 \mathrm{mmHg}$. In the OSA only group, hypercapnia was detected in 1 patient $(4 \%)$ and the average $\mathrm{PaCO}_{2}$ was $36.25 \pm 6.11 \mathrm{mmHg}$. Thus, our investigation shows that patients with overlap syndrome experience longer and more severe nighttime desaturations that disturb gas exchange parameters in comparison to OSA patients with similar AHI

The mechanisms responsible for the gas exchange abnormalities in overlap syndrome are complex. Radwan et al [95] compared the breathing pattern and $\mathrm{CO}_{2}$ response in 11 obese male overlap syndrome patients, 20 obese male OSAS patients with normal lung function, and 13 healthy nonobese controls. Overlap patients with hypercapnia had both blunted ventilatory and mouth occlusion pressure responses to $\mathrm{CO}_{2}$ and their ventilatory response may also be disturbed. The repetitive inspiratory effort against an occluded airway and intermittent hypoxia may be deleterious for the inspiratory muscles in severe OSA. In overlap syndrome patients, this increased fatiguability is even more accentuated, which is related to the mechanical disadvantage of chest wall hyperinflation and reduced functional residual capacity [96].

Moreover, it is established that overlap syndrome patients hypoventilate not only during the night but also during the day. The reason is still unknown. When measured, their chemosensitivity is reduced compared to those with OSA alone. It is elusive whether this is a cause or an effect of the overlap syndrome [95]. It is interesting to speculate that overlap syndrome patients have a genetic predisposition to hypercapnia, or that the higher $\mathrm{PaCO}_{2}$ reflects the increased muscle load in those with both increased upper and lower airway resistance. Inflammation, nocturnal $\mathrm{PaCO}_{2}$ elevations, and/or obesity (for example, leptin has been implicated as a modulator of respiratory drive) may be the triggers changing the $\mathrm{PaCO}_{2}$ setpoint [97].

In summary, the pathophysiology of sleep disordered breathing is complex in overlap syndrome and mainly associated with upper and lower airway obstruction and a reduction in respiratory drive. Hyperinflation may cause fatigue of respiratory muscles. Moreover, the functional residual capacity is reduced because of the supine posture and sleep state which predisposes the patient to ventilation/perfusion mismatch.

\subsubsection{Pulmonary haemodynamics and right heart failure}

OSAS patients may have sustained pulmonary hypertension $(\mathrm{PH})[98,99,100]$ and the risk for its development increases further in the presence of COPD, obesity or both [101,102]. Chaouat et al [87] observed that the prevalence of $\mathrm{PH}$ was $42 \%$ in overlap syndrome compared with OSA alone (13\%). They found that the main determinants of pulmonary hypertension in overlap syndrome were daytime arterial blood gases and $\mathrm{FEV}_{1}$. Moreover, overlap patients often have relatively mild abnormalities (spirometry or oxygenation), especially when compared to COPD-only patients with pulmonary hypertension. Overlap patients with pulmonary hypertension have an average $\mathrm{FEV}_{1}$ of $1.8 \mathrm{~L}, \mathrm{FEV}_{1} / \mathrm{FVC}$ of 0.64 , and awake $\mathrm{PaO}_{2}$ of $64 \mathrm{~mm} \mathrm{Hg}$. COPD-only patients with pulmonary hypertension have more severe obstructive disease, with $\mathrm{FEV}_{1}<1 \mathrm{~L}, \mathrm{FEV}_{1} / \mathrm{FVC}<0.50$, and awake $\mathrm{PaO}_{2}<55 \mathrm{mmHg}$. Fletcher [17] demonstrated that in overlap syndrome, $\mathrm{FEV}_{1} / \mathrm{FVC}$ was $60 \%$. Patients with COPD and daytime normoxia who have only nocturnal oxygen desaturation generally do not develop substantial 
pulmonary hypertension [38]. PH is usually observed in COPD patients with daytime $\mathrm{PaO}_{2}<55 \pm 5 \mathrm{mmHg}$. According to Chaouat et al [87], $\mathrm{PH}$ develops in patients with overlap syndrome at even higher daytime $\mathrm{PaO}_{2}$ levels $\left(\mathrm{PaO}_{2}>66 \pm 10 \mathrm{mmHg}\right)$ than in patients with COPD.The mean $\mathrm{PaO}_{2}$ in sleep is certainly lower due to the synergistic effect that both disorders have on pulmonary haemodynamics and gas exchange. Hawrylkiewicz and colleagues observed that $16 \%$ of OSA patients had pulmonary hypertension compared with $86 \%$ of those with overlap syndrome [103]. In regression analysis, traditional markers of OSA severity, such as the AHI or oxygen saturation nadir, have generally not correlated with the presence of pulmonary hypertension. Even patients with severe OSA alone do not tend to develop marked pulmonary hypertension if they are free from other cardiopulmonary diseases [102]. The degree of pulmonary hypertension if any, is mild and of uncertain clinical importance $[37,103,104]$.

In our overlap group, pulmonary hypertension was detected in $84.6 \%$ of patients who had an average systolic pulmonary pressure of $38.87 \mathrm{mmHg}$. In the group of patients with OSA, pulmonary hypertension was found in only $47.8 \%$ with an average systolic pulmonary pressure of $34.16 \mathrm{mmHg}$. Both the time spent at $\mathrm{SaO}_{2}<90 \%(57.2 \%$ vs. $34.8 \%)$ and the average desaturation index (12.3\% vs $6.9 \%)$ were greater in the overlap vs OSA group. In overlap patients, the average daytime $\mathrm{PaO}_{2}$ was $61.67 \pm 5.78 \mathrm{mmHg}$ vs $75.59 \pm 8.43 \mathrm{mmHg}$ in those with OSA; the average daytime $\mathrm{PaCO}_{2}$ was $52.14 \pm 11.39 \mathrm{mmHg}$ vs $36.25 \pm 6.11 \mathrm{mmHg}$ in the OSA only group.

The ventilatory parameters in overlap patients were disproportionate to the level of gas exchange parameters and poorer than in the OSA only group. Comparing those with overlap syndrome to those with OSA, forced vital capacity (FVC) was $55.5 \pm 24.5 \%$ vs $77.25 \pm 19.6 \%$; forced expiratory volume in $1 \mathrm{~s}\left(\mathrm{FEV}_{1}\right)$ was $53.5 \pm 10.87 \%$ vs $62.25 \pm 20.22 ; \mathrm{FEV}_{1} / \mathrm{FVC}$ was $64.46 \pm 9.19 \%$ vs $86.9 \pm 8.85 \%$, respectively.

According to our results, the degree of $\mathrm{PH}$ was of similar range in both patient groups. The prevalence of pulmonary hypertension in the overlap syndrome was almost two fold greater than in the OSA only group. It is, however, disproportionate to what should be expected from the gas exchange and ventilatory parameters. Before making final conclusions, we should point out that our study was performed in patients with extreme obesity and that pulmonary hypertension was determined by echocardiography which may not be the most accurate measure of pulmonary pressures. The cardiovascular comorbidity, smoking status as well as the higher BMI in overlap syndrome prevented the precise analysis of the clinical factors associated with PAP in overlap and OSA patients.

In summary, in overlap patients, nocturnal desaturation is greater, lasts longer, and is associated with more pronounced daytime hypoxemia and hypercapnia. The combination of OSA and COPD may be associated with increased pulmonary and systemic blood pressures as well as greater cardiovascular morbidity. 


\subsubsection{Mortality}

Mortality in patients with the overlap syndrome has not been well studied until recently. COPD patients frequently die from cardiovascular disease predominantly at night. It can be speculated that some of these patients may have had the overlap syndrome. Similarly, OSA patients have also been shown to die disproportionately at night, compared to control groups, who are at greatest risk during the morning hours [105]. Tachyarhythmias are very likely to be responsible for nighttime deaths in both patient groups. In COPD patients, ventricular premature contractions occur commonlyin sleep when the $\mathrm{SaO} 2$ is $<80 \%$. In OSA patients, the entire spectrum of cardiac arrhythmias may be observed. Olmetti et al [106] showed that in COPD patients with concomitant OSA, tachyarrhythmias are more common.

The diagnosis of concomitant COPD and reduced $\mathrm{FEV}_{1}$ or smoking history are markers for increased mortality in OSA patients [107-109]. In a univariate analysis, COPD conferred a 7fold risk of death in OSA patients [108]. Vice versa, comorbid OSA was recently reported to increase mortality in patients with COPD. Marin et al [47] presented outcome data on patients with COPD and patients with the overlap syndrome. After a median follow-up of over 9 years, all-cause mortality was higher in the untreated (no CPAP) overlap group (42.2\%) than in the COPD-only group (24.2\%). After adjustment for COPD severity, comorbid OSA remained a risk factor for death. An intriguing issue in that study is that OSA may also contribute to an increased incidence of COPD exacerbations, which may accelerate lung-function decline and lead to increased mortality [48,49].

Mermigkis et al demonstrated that, in addition to the increased morbidity and mortality, patients with the overlap syndrome also have significantly worse quality of life (measured with the St George's Respiratory Questionnaire), when compared to COPD-only controls [110]. The overlap syndrome patients in their study were COPD patients with habitual snoring but without excessive daytime sleepiness or elevated Epworth sleepiness score which underscores how difficult clinical diagnosis and screening of snoring in non-sleepy COPD patients may be.

\subsection{Inflammation, oxidative stress and cardiovascular and metabolic comorbidity in overlap}

The exact mechanisms that account for the increased morbidity and mortality risk in overlap syndrome are not known exactly. Increased risk of death may be due to prolonged hypoxia. Nighttime hypercapnia may also be important. There is enough evidence that both COPD and OSA have systemic consequences since both cause inflammation and oxidative stress.

\subsubsection{Inflammation and oxidative stress}

Systemic inflammation is being recognized as a risk factor for a number of complications including atherosclerosis [111]. It is a well-established factor in the pathogenesis of cardiovascular disease (CVD) [112]. There is growing recognition that COPD is a systemic disease $[113,114]$ with multiple effects on end-organs including those in the cardiovascular system $[115,116]$.

Patients with OSA experience persistent low grade inflammation, mainly attributed to repetitive episodes of hypoxia/ reoxygenation during apneas and hypopneas while asleep. 
This inflammation is associated with increased arterial stiffness, blood pressure $[117,118]$ and increased risk for hypertension, heart failure, stroke, and cardiovascular mortality. The molecular pathways of systemic inflammation in OSA and COPD may be similar, suggesting a multiplicative effect in overlap syndrome.

CRP is an acute phase protein that contributes to atherosclerosis. Its plasma levels are elevated in OSA, but obesity is the major confounder because there is no evidence for an independent relationship between OSA and CRP $[119,120]$. IL-6, another inflammatory marker, is increased in OSA even after adjustment for BMI [121]. Further, IL-6 and CRP are elevated in stable COPD patients and increase during exacerbations [122,123].

$\mathrm{NF}-\mathrm{kB}$ is a regulator of inflammatory gene expression and controls the synthesis of cytokines (TNF- $\alpha$, IL-8) [112] that increase expression of adhesion molecules and contribute to atherosclerosis [124]. Hypoxia is the major trigger for the activation of both adaptive and maladaptive transcription factors. Ryan et al [125] showed that sustained hypoxia is responsible for the expression of adaptive hypoxia inducible factor (HIF)-a molecule promoting the expression of genes which stimulate tissue perfusion and oxygenation. Intermittent hypoxia (apnea/ hypopnea events in OSA, NOD in REM induced hypoventilation of COPD patients and overlap patients) is a trigger for NF-kB activation [112]. Thus, we hypothesize that, in OSAS as well as in COPD with overlap, there may be synergistic activation of "overlapping" pathways leading to inflammation. This hypothesis explains the evidence of increased inflammation observed in both COPD and OSA. TNF- $\alpha$ and IL- 8 are elevated in COPD and OSA when compared to control subjects [126]. Both molecules are well established risk factors for coronary artery disease and heart failure [127].

Furthermore, oxidative stress occurs in COPD and OSAS and is associated with increased ROS $[128,129]$ which are produced by intrapulmonary leukocytes in COPD and circulating leukocytes in OSA [128,130]. Although ROS are important physiologic regulators in many signaling pathways, their increased production may cause abnormal oxidation of DNA, proteins and lipids and may contribute to vascular endothelial dysfunction [131].

In our investigation, we tried to compare the degree of oxidative stress, measured by the urinary concentration of 8-isoprostanes. The study was performed in 26 overlap patients and 23 age and AHI matched OSA patients. None of them had been treated with CPAP or oxygen. An overnight urine sample was collected and the levels of urinary 8-isoprostane were determined by HRAM (high resolution accurate mass) mass spectrometry on a LTQ Orbitrap ${ }^{\circledR}$ Discovery (ThetmoScientific Co, USA) mass spectrometer equipped with a Surveyor ${ }^{\circledR}$ Plus HPLC system and IonMax ${ }^{\circledR}$ electrospray ionization module. The analyses were performed using the stable isotope dilution method in negative ionization mode with a HESI II (heated electrospray ionization) source type. The concentration and purification of 8-isoprostane from urine samples was processed by affinity sorbent (Cayman Chemical, USA), according to the manufacturer's protocol. The urinary isoprostane levels were standardized to the levels of urinary creatinine which were measured using the enzyme method (Creatinine plus version 2 (CREP2), Cobas Integra (Roche)). In overlap patients, the average values were higher than in OSA patients, $0.251 \pm 0.10 \mathrm{pg} / \mathrm{mkmol} / \mathrm{cre}$ vs. $0.185 \pm 0.06 \mathrm{pg} / \mathrm{mkmol} / \mathrm{cre}, \mathrm{p}<0.05$. The urinary isoprostane levels did not correlate with the respiratory disturbance parameters (AHI, average 
desaturation, time of sleep at $\mathrm{SaO} 2<90 \%)$, gas exchange parameters $(\mathrm{PaO} 2 / \mathrm{PaCO} 2)$ or with the ventilatory parameters $\left(\mathrm{FVC}, \mathrm{FEV}_{1}, \mathrm{FEV}_{1} / \mathrm{FVC}\right)$.

We confirmed that in overlap patients the degree of oxidative stress is higher irrespective of the parameters mentioned above. The exact mechanisms of oxidative stress as well as its consequences were not determined in our study.

Abnormally activated leucocytes in COPD and OSA may also be a mechanism for atherosclerosis [112]. A systemic metaanalysis has shown that circulating neutrophils are elevated in COPD patients [132]. In vivo studies demonstrate decreased neutrophil apoptosis in OSA patients and increased expression of adhesion molecules [133]. The adhesion of these cells to endothelium is a key step in atherosclerosis and endothelial dysfunction.

In summary, the "overlapping pathways" activating inflammation and oxidative stress in overlap patients are poorly understood and further investigations at the molecular level are required for a better understanding of these processes and their abrogation in clinical practice.

\subsubsection{Cardiovacular comorbidity and oxidative stress in overlap vs OSA}

\subsubsection{Hypertension, target organ damage, and oxidative stress}

Large scale epidemiological studies have demonstrated an independent relationship between OSAS and cardiovascular disorders, particularly systemic hypertension [134,135], but also coronary heart disease, congestive heart failure, and stroke [136,137]. The presence of moderate to severe OSA as indicated by an AHI $>15$ events/h leads to a relative risk of 2,89 of developing hypertension over 8 years, after adjustment for potential confounders. The prevalence of hypertension is over $50 \%$ in OSAS patients. Hypertension in OSAS patients is particularly nocturnal and potentially driven by sleep disordered breathing.

We performed BP monitoring in 20 (77\%) of the overlap and $12(52 \%)$ of the OSA patients in our study. We compared the haemodynamic characteristics and clinical factors associated with them. BP was measured according to European Society of Hypertension (ESH)/European Society of Cardiology (ESC) guidelines. The following parameters were measured: systolic BP (SBP) and diastolic BP (DBP). Hypertension was defined as a SBP $>140 \mathrm{mmHg}$ and/or a DBP $>90 \mathrm{mmHg}$. Ambulatory BP monitoring (ABPM) was performed with a BOSO device (Bosch \&Sons, Gruningen, Germany). The measurements were made every 20 min over $24 \mathrm{~h}$. Daytime (07:00-22:00 h) hypertension was defined as daytime SBP $>135 \mathrm{mmHg}$ and/or daytime DBP $>85 \mathrm{mmHg}$, and nocturnal (22.00-07:00 h) hypertension as SBP $>120 \mathrm{mmHg}$ and/or nocturnal $\mathrm{DBP}>70 \mathrm{mmHg}$. Dipper pattern was defined by a nocturnal fall of BP $>10 \%$. Twenty of the overlap patients and 12 of those with OSA agreed to undergo the procedure.

In the overlap group, $75 \%$ (15) were non-dippers and 25\% dippers. Nocturnal hypertension was found in $12(60 \%)$ patients. The daytime systolic and diastolic BP's were $121.93 \pm 17.09$ $\mathrm{mmHg}$ and $70.93 \pm 8.12 \mathrm{mmHg}$. The nocturnal SBP and DBP were $112.76 \pm 5.38 \mathrm{mmHg}$ and $68.16 \pm 3.34 \mathrm{mmHg}$. In OSA patients, $58 \%$ (7) were non-dippers and $42 \%$ dippers. Nocturnal hypertension was found in $7(58 \%)$ patients. The daytime systolic and diastolic BP were $138.3 \pm 13.64 \mathrm{mmHg}$ and $84.38 \pm 8.20 \mathrm{mmHg}$. The nocturmal SBP and DBP were $133.90 \pm 18.89$ 
$\mathrm{mmHg}$ and $76.80 \pm 11.65 \mathrm{mmHg}$. We could not find an association between any of the studied parameters; anthropometric (age, BMI, waist and neck circumference), sleep (AHI, average desaturation, time of sleep at $\left.\mathrm{SaO}_{2}<90 \%\right)$, gas exchange $\left(\mathrm{PaO}_{2}\right.$ and $\left.\mathrm{PaCO}_{2}\right)$ and ventilatory $\left(\mathrm{FEV}_{1}, \mathrm{FVC}\right)$ and daytime/nighttime systolic/diastolic $\mathrm{BP}$ in any of the groups. Though the level of urinary isoprostanes was higher in the overlap group, they did not correlate with the haemodynamic characteristics either.

An echocardiogram and carotid ultrasonography were also performed to compare the degree of target organ damage in overlap and OSA patients and to explore the role of urinary 8isoprostanes. The echocardiogram was performed using a PhilipsiE33 machine. The examination was performed in M-mode with two-dimensional (2D) guidance in the long axis of the left parasternal view. LV internal end-diastolic and end-systolic diameters, as well as interventricular septum and posterior wall thicknesses were measured over five consecutive cycles. Systolic function was assessed by the LVEF according to the Teicholz formula. LV mass (LVM) was measured according to the Penn convention using the Devereux formula and was normalised for body surface area (BSA) to derive the LVM index (LVMI). LVH was defined as an LVMI of $>111 \mathrm{~g} / \mathrm{m}^{2}$ in males and of $>106 \mathrm{~g} / \mathrm{m}^{2}$ in females. The relative wall thickness (RWT) was calculated as the ratio $(2 \times P W T) / L V I D d$. All echocardiograms were performed by the same experienced echocardiographer.

In OSA and overlap patients, LVMI and RWT were, respectively: LVMI 123.97 vs $142.1 \mathrm{~g} / \mathrm{m} 2$, $\mathrm{p}=0.013$; RWT -0.44 vs $0.46, \mathrm{p}=0.045$. The LVMI and RWT were significantly higher in the overlap patients, even after adjustment for AHI, BMI, SBP and DBP. Microalbumiuria was measured and standardized to creatinine excretion and given as ratio $-\mathrm{mg} / \mathrm{mkmol} / \mathrm{l}$ Creat. The micralbuminuria level in OSA was $5.69 \mathrm{mg} / \mathrm{mkmol} /$ creat. In the overlap patients, it was significantly higher, $26.17 \mathrm{mg} / \mathrm{mkmol} / \mathrm{creat}$, irrespective of confounding variables $(\mathrm{p}=0.041) .8$ Urinary isoprostane levels correlated with neither LVMI nor the degree of microalbuminuria.

\subsubsection{Atherosclerosis and oxidative stress}

Patients with severe OSA are more likely to die of cardiovascular causes than those without OSAS [45]. While the absolute risk attributable to SDB is relatively small at an individual level, the high OSA prevalence makes it an important contributor to cardiovascular morbidity and mortality at populational levels. Several reports have stated that OSA may also contribute to coronary heart disease [138]. Studies utilizing carotid ultrasonography have shown severe OSA to be associated with increased intima-media thickness (IMT) which is a marker of atherosclerosis [139]

In our investigation, we assessed carotid artery IMT by B-mode ultrasound scanning with an 11-MHz linear phase array transducer. Bilateral IMT measurements were obtained in the distal $10 \mathrm{~mm}$ of the common carotid artery. The IMT was defined as the distance between the leading edge of the luminal echo to that of the media/adventitia echo and analyzed with a computerized edge-detection system. Three end-diastolic frames were selected, digitized, and analyzed for the mean IMT, and the average reading from these 3 frames was calculated for both right and left carotid arteries. The sole carotid scan operator was blinded to the clinical status of the studied subjects and was not involved in the clinical assessment. IMT was almost similar in 
both groups. In the overlap patients the average IMT was 0.90 while in the overlap group it was 0.89 .

In our study, nocturnal blood pressure abnormalities were similar in overlap and OSA only patients. Those with overlap syndrome had greater target organ damage (cardiac-left ventricular hypertrophy and renal - microalbuminuria) in comparison with age and AHI matched OSA patients, even after adjustment for confounders (BMI, average desaturation, time of sleep at $\mathrm{SaO}_{2}<90 \%$, duration of hypertension, current therapy). Giving this statement we should point out that it refers to OSA of moderate severity and overlap patients with moderate SDB and airflow obstruction. Both patient groups had extreme obesity. A disadvantage of the study is that the historical information for the management of hypertension was self reported and thus subjective.

\subsubsection{Metabolic disorders in overlap and OSA patients}

Many studies confirm the greater prevalence of metabolic syndrome in OSA patients. Both glucose and lipid metabolism abnormalities have been reported [140]. The role of intermittent hypoxia, sympathetic activation and sleep fragmentation has been reviewed [141]. Comparative data regarding the metabolic disturbances in overlap syndrome, COPD, and OSA are still lacking. The effect of both disorders in overlap syndrome, their additive and/or synergistic interaction, and physiological pathways on metabolism is not well understood.

In our investigation, we measured parameters of glucose metabolism in the overlap and OSA patients. A correlation analysis with oxidative stress markers (8-isoprostanes) was performed. Using enzymatic colorimetry plasma levels of total cholesterol, triglycerides, high-density lipoprotein cholesterol, low-density lipoprotein cholesterol (using the Friedwald formula), glucose, immuno-reactive insulin, and HOMA-index were measured. An oral glucose tolerance test (OGTT) was performed to detect glucose metabolism abnormalities.

Diabetes was found in $30 \%$ of the overlap patients, $50 \%$ were healthy, and $20 \%$ had an impaired glucose tolerance. In OSA patients, 33\% were diabetic, $44 \%$ were healthy, and an impaired glucose tolerance was found in $23 \%$. Although the average parameters tended to be higher in overlap vs OSA patients resp-IRI-21.04 $\pm 15.46 \mathrm{mU} / \mathrm{l}$ vs $18.37 \pm 9.95 \mathrm{mU} / \mathrm{l}$; average fasting blood glucose- $6.19 \pm 2.86 \mathrm{mmol} / 1$ vs $5.73 \pm 2.03 \mathrm{mmol} / \mathrm{l}$, HOMA-I $5.52 \pm 4.03$ vs $4.84 \pm 2.64$; there were no statistically significant differences. Only the glycosylated hemoglobin was significantly higher-6.51 \pm 1.24 vs $5.91 \pm 1.07, \mathrm{p}<0.05$ and remained significantly different after adjusting for confounders (age, $\mathrm{BMI}, \mathrm{AHI}$ ). $\mathrm{FEV}_{1}, \mathrm{PaO}_{2}$, and $\mathrm{PaCO}_{2}$ did not correlate any of the glucometabolic parameters. A positive correlation between $\mathrm{HbA1c}$ and urinary 8-isoprostanes was established, $\mathrm{p}=0.023$. The lipid profiles in both groups were similar. Dyslipidemia was present in $50 \%$ of overlap and $47 \%$ of OSA patients. In OSA and overlap patients, they were respectively-HDL $1.24 \pm 0.4 \mathrm{mmol} / \mathrm{l}$ vs $1.20 \pm 0.23 \mathrm{mmol} / \mathrm{l}$; LDL $3.13 \pm 0.81 \mathrm{mmol} / \mathrm{l}$ vs $3.14 \pm 1.00 \mathrm{mmol} / \mathrm{l}$; Tot chol $-5.30 \pm 0.95$ vs $5.27 \pm 1.6 \mathrm{mmol} / \mathrm{l}$; Triglycerides $-2.82 \pm 1.24$ vs $2.06 \pm 1.03 \mathrm{mmol} / \mathrm{l}$. FEV $\mathrm{PaO}_{2}, \mathrm{PaCO}_{2}$ and urinary isoprostanes did not correlate with any of the lipid profile parameters. 
In conclusion, our study showed that the prevalence of glucometabolic abnormalities in the overlap and OSA patients was similar. The glucometabolic parameters for patients with overlap syndrome, however, were worse in comparison with OSA only. HbA1C levels were associated with the level of oxidative stress-urinary 8-isoprostanes. The prevalence of dyslipidemia and lipid profile parameters in both groups were almost identical and were not associated with the marker of oxidative stress. Our OSA subjects had moderately severe OSA and overlap syndrome patients had moderate SDB and airflow obstruction. Both patient groups had extreme obesity.

\subsection{Sleep quality in overlap}

In OSAS patients, one of the most common symptoms is excessive daytime somnolence, which results from disrupted sleep or/and nighttime oxygen desaturation [142,143]. Mild to moderate COPD patients usually do not have significant daytime sleepiness. Fatigue and tiredness are more common $[59,144]$.

Sanders et al [55] studied 1132 patients with mild COPD and observed that COPD only patients had minimally perturbed sleep in the absence of OSA. Sleep architecture did not correlate with the level of airflow obstruction. There were small but not statistically significant differences between patients with or without COPD with regards to Epworth Sleepiness Scale (ESS), total sleep time, arousal index, lower total sleep time, and sleep efficiency. Only small differences were found between patients with OSA alone or those with both disorders, suggesting that sleep quality in overlap patients is mainly influenced by the presence of OSA. This is confirmed by Redline et al [56]. They demonstrated that sleep structure characteristics did not change in subjects with a history of lung disease but sleep stage distributions varied according to AHI level.

Analysing the data from our investigation, we found that the ESS was the same in patients with overlap syndrome and OSA only. The average ESS score in the overlap group was $15 \pm 4.3$ while in the OSA only patients, it was $14 \pm 5.8$. The sleep study characteristics in OSA and overlap were respectively - stage 1-30.1 $\pm 9.59 / 27.04 \pm 7.7 \mathrm{~min}$; stage $2-27.5 \pm 11.3 / 33.7 \pm 716.5 \mathrm{~min}$; stage $3+4-28.35 \pm 17.12 / 31.87 \pm 16.43 \mathrm{~min}$; AI -31.6 vs 36.4 apneas/h; sleep efficiency was $69 \%$ in OSA and $64 \%$ in overlap patients. Though the duration of sleep with $\mathrm{SaO}_{2}<90 \%$ was much longer for the overlap patients, it correlated neither to the level of 8-isoprostanes (oxidative stress) nor to the ESS. The degree of airway obstruction (measured by $\mathrm{FEV}_{1}$ ) did not correlate with sleep stage distribution, AHI, AI, or ESS.

\subsection{Clinical presentation}

The most common symptoms of OSA patients are snoring, excessive daytime sleepiness, and deterioration of quality of life $[145,146]$. COPD patients, on the other hand, may present with cough, sputum production, and/or dyspnea [64]. Nevertheless, overlap patients possess a unique characteristic, which sets them apart from either COPD or OSA patients. A number of studies compare the clinical presentation of overlap patients to those of OSAS-only patients. 
Chaouat et al [87] stated that compared to the OSA only group, the overlap patients tended to be older, had hypoxemia and hypercapnia more frequently and had higher mean pulmonary artery pressures but similar body mass index (BMI). O'Brien and Whitman [147] found that overlap patients were older and less obese. Resta et al [148] showed that overlap patients had higher $\mathrm{PaCO}_{2}$, but similar apnea-hypopnea indices (AHI).

Kessler noted that in OSAS patients exhibiting permanent pulmonary hypertension, bronchial obstruction is generally not severe and the level of hypoxemia and hypercapnia is modest. Therefore, chronic airway obstruction in these patients may be asymptomatic. These findings suggest that the performance of pulmonary function tests in all patients diagnosed with OSAS by a polysomnogram might be beneficial to detect occult airflow obstruction [149].

In our investigation, we observed 26 patients with overlap syndrome and compared them to 23 age and $\mathrm{AHI}$ matched patients with OSA only. In the overlap group, the mean $\mathrm{FEV}_{1}$ was $53.5 \pm 10.87 \%$; FVC-55.5 $\pm 24.5 \%$; FEV $/$ FVC-64.46 $\pm 9.19 \%$ The average daytime $\mathrm{PaO}_{2}$ was $61.67 \pm 5.78 \mathrm{mmHg}$. Five (19\%) patients had daytime hypercapnia and their average daytime $\mathrm{PaCO}_{2}$ was $52.14 \pm 11.39 \mathrm{mmHg}$. The patients had the following anthropometric charactersistics: mean age- $46.83 \pm 8.62 \mathrm{y}$; BMI- $41.89 \pm 4.57 \mathrm{~kg} / \mathrm{m} 2$; waist circumference $-133.11 \pm 10.94 \mathrm{~cm}$; neck circumference $-48.54 \pm 3.92 \mathrm{~cm}$. One $(3 \%)$ was a non-smoker. In our overlap group, pulmonary hypertension was detected in $84.6 \%$ with an average systolic pulmonary pressure-38.87 $\mathrm{mmHg}$.

A group of 23 age and AHI matched OSA patients were selected from the registry of sleep lab patients. The average daytime $\mathrm{PaO}_{2}$ was $75.59 \pm 8.43 \mathrm{mmHg}$. None of the patients had hypercapnia and the average daytime $\mathrm{PaCO}_{2}$ was $36.25 \pm 6.11 \mathrm{mmHg}$. The patients had the following anthropometric charactersistics: mean age-49.95 $\pm 10.54 \mathrm{y}$; BMI-37.47 $\pm 7.98 \mathrm{~kg} / \mathrm{m} 2$; waist circumference $-126.43 \pm 11.28 \mathrm{~cm}$; neck circumference $-45.46 \pm 4.49 \mathrm{~cm}$; Four $(17 \%)$ were nonsmokers. The ventilatory parameters in the OSA only group were: FVC-77.25 $\pm 19.6 \%$; $\mathrm{FEV}_{1}-62.25 \pm 20.22 \% ; \mathrm{FEV}_{1} / \mathrm{FVC}-86.9 \pm 8.85 \%$. In the group of patients with OSA only, pulmonary hypertension was found in $47.8 \%$ with average systolic pulmonary pressure $-34.16 \mathrm{mmHg}$. The Epworth sleepiness score (ESS) was similar in both groups-overlap- $15 \pm 4.3$ vs OSA only $14 \pm 5.8$.

According to our results the overlap patients were younger, had increased BMI, waist and neck circumferences in comparison to the OSA only patients. The AHI, AI, the duration of sleep with $\mathrm{SaO}_{2}<90 \%$ as well as the daytime gas exchange abnormalities were more severe in the overlap group. The sleep complaints however were almost identical. The degree of PH was similar in both patient groups. The prevalence of pulmonary hypertension in the overlap syndrome was almost two fold greater than in the OSA only group. It was, however, disproportionate to what should be expected from the gas exchange parameters. As our results are not in agreement to those mentioned above, we should point out that our investigation was performed in patients with extreme obesity, which more or less reflects the respiratory drive, respiratory mechanics and pulmonary haemodynamics. They should be compared to patients with a moderate degree of sleep disordered breathing and excessive sleepiness and/or disturbed sleep. 


\subsection{Current guidelines and recommendations in the diagnostic approach to overlap syndrome in OSA patients}

Nocturnal polysomnography is recommended in COPD patients whose symptoms suggest coexistent OSA. This encompasses COPD patients with daytime hypercapnia and moderately reduced $\mathrm{FEV}_{1}$; $\mathrm{COPD}$ snorers, or those who develop headache after nocturnal oxygen therapy [25,64]. Apneas while asleep and daytime sleepiness are highly suggestive of OSA [65]. However, the presence of concomitant OSA is often difficult to predict. A large number of patients with OSA do not have daytime hypercapnia or headache and some of them are not obese. Daytime sleepiness is often absent. The significant cardiovascular morbidity and mortality related to untreated OSA and its reversibility with CPAP treatment strongly demands a more aggressive approach in diagnosing coexistent OSA among patients with COPD [150,151].

The recognition and diagnosis of COPD may be challenging in patients with OSA. Smoking history should always be obtained. COPD among OSA patients should be suspected if daytime hypercapnia, pulmonary hypertension, and nocturnal tachyarrhythmias are present. $[42,87,106,148]$. Chaouat et al [87] performed a study in 265 patients. They found that the prevalence of daytime hypercapnia was $27 \%$ in the 30 patients with associated COPD and $8 \%$ in the 235 patients without COPD. Daytime hypercapnia was observed in 11\% of 1141 OSA patients who were free of COPD and was related to the severity of obesity [152]. Pulmonary hypertension is observed in 75\% of patients with coexistent OSA and COPD [42] and in only $12 \%-20 \%$ of unselected OSA patients [102]. Patients with coexistent OSA and COPD are 2.53 times more likely to experience tachyarrhythmias during sleep than patients with OSA alone [106].

In summary, patients with OSA who do not carry a diagnosis of COPD but have daytime hypercapnia, pulmonary hypertension, and/or nocturnal tachyarrhythmias should undergo pulmonary function testing (table 2). On the other hand, COPD patients with witnessed apneas, daytime sleepiness, obese snorers, those who have daytime hypercapnia and/or pulmonary hypertension, and/or daytime hypoxaemia disproportionate to their $\mathrm{FEV}_{1}$ should undergo a polysomnography study.

\section{OSA}

Daytime hypercapnia disproportionate to obesity

Pulmonary hypertension

Tachyarrhythmias

Table 2. Indications for performing a pulmonary function testing in OSA 


\section{Treatment of nod in copd patients}

\subsection{Medications - bronchodilators, corticosteroids, hypnotics}

\subsubsection{Effect on sleep quality}

Ipratropium improves sleep quality [153] in patients with moderate to severe COPD, while tiotropium has no effect [154], at least not in patients with severe COPD. Data regarding theophylline have been variable, with some studies showing sleep disturbances [155], and others showing no changes [156-58]. 28\% of COPD patients use hypnotics because of insomnia and other sleep disorders. Benzodiazepines are not recommended as they worsen nocturnal hypoxemia [159]. Non-benzodiazepine compounds like Zolpidem are safer [160].

\subsubsection{Effect on $N O D$}

Bronchodilators have variable effects on sleep quality but they significantly improve NOD. Theophylline [155,157], ipratropium [153], and tiotropium inhalers [154] have shown improvements in NOD. Martin et al studied the effect of ipratropium, taken 4 times a day in 36 patients with moderate to severe COPD $\left(\mathrm{FEV}_{1}<65 \%\right)$ [153]. After a month of treatment, nocturnal oxygen saturation decreased, subjective sleep complaints improved, and total REM time increased. Tiotropium also improved nocturnal oxygen saturation but sleep quality remained unchanged [154]. Long-acting $\beta 2$ agonists have similar benefits [161]. Oral steroids in stable COPD improve nocturnal oxygen desaturation and increase total sleep time [162]. Despite the lack of data, we might suggest that inhaled corticosteroids may have a similar effect.

\subsection{Oxygen}

\subsubsection{Effect on sleep quality}

A limited number of studies have examined the effect of oxygen therapy on sleep. A decrease in sleep latency, increase in total sleep duration, and REM were noted by Calverley et al [6]. Fleetham et al [57] noted no improvements in total sleep time (TST), sleep stages or frequency of arousals with the addition of oxygen.

\subsubsection{Effect on $N O D$}

In COPD patients with severe daytime hypoxemia (49-52 $\mathrm{mm} \mathrm{Hg}$ ), and nocturnal desaturations, it has been clearly established in both the British Medical Research Council (MRC) LongTerm Domiciliary Oxygen Therapy Trial [164] and the Nocturnal Oxygen Therapy Trial (NOTT) [165] that continuous oxygen therapy improves survival. This improvement was seen in comparison to supplemental oxygen administered only at night. COPD patients with hypoxemia only during sleep may also have increased mortality risk [166]. The correction of nocturnal hypoxaemia alone in patients with daytime normoxia does not significantly improve 
pulmonary haemodynamics or mortality [38], but it may improve sleep quality and is frequently prescribed [6].

Oxygen therapy for COPD patients with moderate daytime hypoxaemia and nocturnal desaturations remains very controversial. After a 3 year follow-up, no difference in survival among COPD patients with moderate hypoxaemia $\left(\mathrm{PaO}_{2} 56\right.$ and $\left.69 \mathrm{~mm} \mathrm{Hg}\right)$ was noted between the supplemental oxygen therapy group (average use of $14 \mathrm{~h} / \mathrm{d}$ ) and the control when [167]. Fletcher et al [168] found no survival benefit in COPD patients with NOD and an awake $\mathrm{PaO}_{2}>60 \mathrm{~mm} \mathrm{Hg}$, when randomized to $3 \mathrm{~L} /$ minute of oxygen or sham control for 36 months. Pulmonary hemodynamics, however, improved in the oxygen therapy group. In a 5-year follow up study, Chaouat et al [39] found no survival advantage in COPD patients with $\mathrm{PaO}_{2}$ 56-69 mm Hg who were randomized to oxygen therapy versus a control group. They found no difference in the progression of COPD to respiratory failure or the development of pulmonary hypertension.

The effect of long-term oxygen therapy on mortality in COPD patients with isolated nocturnal oxyhemoglobin desaturation remains unclear. Pooling together COPD patients with and without nocturnal oxyhemoglobin desaturation may mask the benefit of long-term oxygen therapy on survival in COPD patients with nocturnal oxyhemoglobin desaturation only.

In summary, survival benefit of long term oxygen therapy is attained in COPD patients with severe daytime hypoxaemia. Based on current data, oxygen therapy is unproven in COPD patients with moderate daytime hypoxemia and NOD, or in COPD patients who experience only NOD. Improvement of pulmonary haemodynamics and sleep quality with oxygen is also unproven.

\subsection{Non-invasive positive pressure ventilation (NIPPV)}

The role of NIPPV has been clearly established in COPD patients with an acute exacerbation. Data about its role in stable COPD patients is missing. Studies present mixed results and vary depending on the design. A recent systematic review of NIPPV in severe stable COPD patients was conducted by Kolodziej et al. [169]. They reviewed 9 randomized controlled trials (RCTs) and nine non-RCTs. No improvement in gas exchange with NIPPV among the RCTs was found. In the non-RCTs a reduction in lung hyperinflation and diaphragmatic work of breathing was noted. Improvement in gas exchange was also established [169]. Although NIPPV may have favorable effects, its therapeutic role has not been firmly stated for stable COPD patients. Despite this, the application of NIPPV in medical centres has been increasing. Recommendations from the American College of Chest Physicians (ACCP) were published to help clinicians in guiding therapy with NIPPV in stable COPD patients. According to ACCP guidelines, NIPPV may be considered in stable COPD when symptoms (fatigue, morning headache, daytime hypersomnolence) and one of the following is present: $1 . \mathrm{PaCO}_{2}>55 \mathrm{~mm}$ $\mathrm{Hg}$; (OR) 2. $\mathrm{PaCO}_{2}-50-54 \mathrm{mmHg}$ and $\mathrm{NOD}$ (overnight oximetry with $\mathrm{SaO}_{2}<88 \%$ for $5 \mathrm{~min}$ while on oxygen therapy $>2 \mathrm{~L} /$ minute; (OR) $3 . \mathrm{PaCO}_{2} 50-54 \mathrm{~mm} \mathrm{Hg}$ and hospitalization related to recurrent episodes (>two in a 12-month period) of hypercapnic respiratory failure [170]. 
Two recent results deserve attention. McEvoy et al [171] performed a randomized controlled trial of NIV in patients with stable hypercapnic COPD which showed a significant improvement in adjusted mortality. Little or no change in pulmonary function or daytime blood gases was detected. The improvement in mortality was associated with a worse quality of life with NIV. A second study by Windisch et al [172] also reported mortality improvements with NIV, although compared to historical controls. They used "high-intensity NIV" with very high driving pressures (average inspiratory pressure $28 \mathrm{~cm} \mathrm{H}_{2} \mathrm{O}$, average expiratory pressure $5 \mathrm{~cm}$ $\mathrm{H}_{2} \mathrm{O}$ ) and a high respiratory rate (21 breaths/min). Under these settings, there were also improvements in spirometry and blood gases.

\section{Treatment of nod in copd patients with osa - the overlap syndrome}

The aim of the treatment of patients with overlap is to avoid desaturations and sleep-disordered breathing. Treatment should be individualized according to the degree of OSA and/or COPD severity and in consideration of the co-existing illnesses - obesity, heart failure, pulmonary hypertension. All patients should however be advised about the potential benefits of therapy and the risks of going without it. Although CPAP therapy is a well-established treatment for OSA, it is not suitable for all overlap patients [173,174]. Auto-titrating CPAP is not recommended in COPD and overlap patients. Treatment options may also include oral appliances, additional supplement of oxygen or non-invasive positive pressure ventilation (NPPV).

\subsection{General recommendations and medications}

All patients should be advised of the importance of avoiding factors that increase the severity of upper-airway obstruction such as use of alcohol, smoking, hypnotic agents, and increased weight [175]. Data suggest that treatment of COPD in overlap syndrome will ameliorate nocturnal oxygen desaturation, and may decrease the need for supplemental oxygen in addition to CPAP [83]. Whether treatment of COPD in the overlap syndrome also improves OSA is not known.

\subsection{Oxygen}

The benefit of supplemental oxygen therapy alone in OSA is lacking [176]. After two-weeks of oxygen administration, nocturnal oxygen desaturation is improved, but sleep architecture, arousals, and subjective sleepiness are not. Alford et al applied $4 \mathrm{~L} / \mathrm{min}$ supplemental oxygen to 20 overlap patients; NOD improved, but the duration of obstructive events increased which resulted in an increase of end-apneic PCO2 from $52.8 \mathrm{~mm} \mathrm{Hg}$ to $62.3 \mathrm{~mm} \mathrm{Hg}$. Thus, oxygen alone should not be used for the treatment of the overlap syndrome.

\subsection{Continuous positive airway pressure}

CPAP remains the standard treatment for OSA and is the accepted therapy for overlap syndrome. Its effect however depends on the severity of OSA/COPD and on the presence of 
comorbidities. In some patients CPAP alone may not fully correct hypoxaemia and supplemental oxygen may be required [177]. In hypercapnic COPD patients however it is not recommended.

COPD patients with mild sleep-disordered breathing and severe nocturnal hypoxaemia may not tolerate CPAP. They may be better managed with oxygen. As most of the oxygen trials were performed at the time when polysomnography was not widely used, further evaluation of its benefits in COPD patients with mild sleep apnea should be performed.

CPAP is better tolerated in COPD patients with moderate/severe OSA. Data about its effects on daytime lung function is controversial. Some authors suggest that upper-airway irritation increases lower-airway resistance and correction of repetitive airway collapse might improve pulmonary function [177]. Others postulate that CPAP off-loads the respiratory muscles, decreases hypoventilation, oxygen consumption, and carbon dioxide production. During sleep these muscles may be alleviated by CPAP, since it prevents the increase of upper-airway resistance that occurs in sleep [178]. In severe COPD, CPAP may offset intrinsic PEEP in severe COPD. In 8 COPD-only patients, Mezzanotte et al, [179] applied CPAP for 1-3 weeks. They assessed inspiratory force and endurance and found significant improvements in maximum inspiratory force and 12-min walk test. Improvements have also been observed in daytime oxygenation and hypercapnia, $[180,181]$ and in the number of COPD-related hospital admissions following the start of CPAP treatment for OSA [182].

Conflicting spirometry results have been seen when CPAP is used in the overlap syndrome. A few non-randomized studies have shown improvements in $\mathrm{FEV}_{1}, \mathrm{PaO}_{2}, \mathrm{PaCO}_{2}$, after CPAP initiation $[84,103,180]$. The largest study (55 patients), by de Miguel et al [84] observed significant improvements in $\mathrm{FEV}_{1}, \mathrm{FVC}$, and $\mathrm{PaCO}_{2}$ after 6 months of CPAP therapy. Both spirometry and gas exchange parameters remained improved for 18 months after CPAP cessation.

The addition of long-term CPAP therapy to standard treatment of COPD patients may also improve gas exchange while reducing hospitalization rates in patients with COPD and OSA $[84,180]$. The improvement in gas exchange with CPAP has important implications when assessing the necessity of long term oxygen therapy in patients with coexistent COPD and OSA. Among 55 middle-aged men with daytime hypoxaemia and coexistent COPD and OSA, only $22 \%$ continued to have daytime $\mathrm{PaO}_{2}<60 \mathrm{mmHg}$ after 6 months of CPAP therapy [84]. Furthermore, CPAP therapy reduces elevated pulmonary and systemic arterial pressures in OSA [103,183] which emphasizes the importance of timely diagnosis and treatment of coexistent COPD and OSA. A substantial weight loss in that trial (mean weight loss approximately 15 pounds) could also explain part of the improvement. A negative study by O'Brien found that the overlap patients who were most adherent to CPAP had the greatest decline in lung function [151]. This could reflect bias, since those patients with the most progressive disease and symptoms may have used CPAP the most (or were urged to do so by their physicians). The small number of patients (35), the fact that only one third of them were included in the final analysis, the lack of precise timing of baseline and follow-up pulmonary function testing, makes these data difficult to interpret. 
Long-term follow-up and outcomes of CPAP therapy in the overlap syndrome have only recently been reported. In an observational study, Machado et al [184] evaluated 95 patients with moderate-to-severe OSA and hypoxaemic COPD. Patients were hypoxaemic and hypercapnic at rest. They received long term oxygen therapy (LTOT). 61 patients received $\mathrm{CPAP}$, the remainder were not adherent to ventilatory treatment. The five-year survival was $71 \%$ in the CPAP treated and $26 \%$ in the non-treated group. The adjustment for confounding factors showed that patients treated with CPAP had a significantly lower risk of death.

Marin et al [150] studied 441 patients with overlap syndrome (228 patients were treated with CPAP and 213 not treated) and 210 patients with COPD only for almost ten years. The coexistence of OSA/COPD was associated with an increased mortality (particularly cardiovascular) compared to COPD alone. Secondly, effective CPAP treatment of OSA reduces mortality in overlap patients. Finally, patients with overlap not treated with CPAP were more likely to suffer severe COPD exacerbations and hospitalizations in comparison to the COPD only group. In both studies, however, CPAP was not provided in a randomized, blinded manner.

\subsection{Non-invasive ventilation}

While CPAP therapy is effective in most OSA patients with or without coexistent COPD, bilevel positive airway pressure (PAP) may be useful when overlap patients experience difficulty exhaling against pressure or when, despite the adequate airflow during CPAP titration, intermittent nocturnal hypoxemia persists [185]. This is usually observed in severe COPD patients who hypoventilate during the night. In such cases bilevel devices should be considered. Bilevel PAP delivers a lower expiratory PAP and higher inspiratory PAP thereby augmenting ventilation [186,187]. In overlap patients who experience persistent intermittent nocturnal hypoxemia despite the adequate airflow during CPAP or BiPAP the positive airway pressure can be increased to ameliorate possible residual upper airway resistance. If increased PAP is ineffective or poorly tolerated, supplemental oxygen can be added [188].

The current guidelines suggest initial follow-up within 1 month after the start of PAP treatment. Subsequent visits should be annually or as needed The objective monitoring of PAP compliance is strongly recommended [185]. The close follow-up of patients includes patient education, adjustment of facial interfaces, and treatment of nasal conditions [185].

The effects of bilevel PAP on overlap syndrome have not been evaluated.

In our investigation, we followed 21 overlap patients who were adherent to BiPAP therapy after a period of one month. A slight improvement in ventilatory parameters was detected: $\mathrm{FEV}_{1} 53.5 \pm 10.87 \%$ vs $62.1 \pm 9.18$; FVC- $55.5 \pm 24.5 \%$ vs $64.8 \pm 17.19 \%$ (Figure 3 ). A minor correction of blood exchange abnormalities was also observed (Figure 3). The average daytime $\mathrm{PaO}_{2}$ increased from $61.67 \pm 5.78 \mathrm{mmHg}$ to $69.32 \pm 7.18 \mathrm{mmHg}$ (Figure 3). Hypercapnia was compensated in $43 \%$ of the patients and decreased from $52.14 \pm 11.39 \mathrm{mmHg}$ to $48.32 \pm 8.17 \mathrm{mmHg}$. Though not of statistical significance, oxidative stress, as measured by urinary 8 -isoprostanes, was also lower after one month of BiPAP therapy $-0.251 \pm 0.10$ vs $0.214 \pm 0.12$. The subjective sleepiness (ESS) improved from $15 \pm 4.3$ to $12 \pm 3.8$; this is related to an improvement of sleep disordered breathing. A reduction of IRI was also detected $21.04 \pm 15.46$ vs $19.13 \pm 9.21 \mathrm{mU} / 1$. Our 
data suggests that BiPAP therapy improves gas exchange and ventilatory parameters in overlap partients. It reduces the oxidative stress level and alleviates sleep complaints. Comparative data with CPAP is however missing. Whether long-term NIV would improve outcomes in the overlap syndrome, compared to CPAP is also unknown.

\begin{tabular}{ccc}
\hline & Before BiPAP treatment & After BiPAP ventilation \\
\hline $\mathrm{FVC}(\mathrm{I})$ & 1.52 & 1.61 \\
\hline $\mathrm{FEV}(\mathrm{I})$ & 1.12 & 1.18 \\
\hline $\mathrm{pH}$ & 7.41 & 7.46 \\
\hline $\mathrm{PaO}_{2}(\mathrm{mmHg})$ & 66.8 & 69.9 \\
\hline $\mathrm{PaCO}_{2}(\mathrm{mmHg})$ & 39.5 & 35.9 \\
\hline
\end{tabular}

Figure 3. Representative spirometric and gas exchange parameters before and after treatment with BiPAP for one month from a single patient.

\section{Conclusions}

Sleep disturbances and NOD are common in COPD patients. Those patients with severe disease have both subjective and objective complaints of poor sleep quality and are easily suspected to experience NOD. The challenge to clinicians is to detect NOD among COPD subjects with mild daytime hypoxaemia where the clinical parameters predisposing patients to NOD are not as well recognized.

OSA is an independent, contributing mechanism to NOD in almost half of COPD patients who experience nighttime desaturations. The overlap syndrome though highly prevalent is frequently unrecognized in clinical practice. Daytime sleepiness and naps are not universal for OSA patients and the failure of clinicians to consider SDB in COPD is the reason for its poor detection. Overlap syndrome is associated with greater hypoxaemia and hypercapnia than COPD and OSA alone, which may have cardiovascular implications. Its early recognition and treatment with positive pressure ventilation may reduce morbidity and mortality and is strongly recommended.

According to our investigation, overlap patients have a higher prevalence of metabolic and cardiovascular disorders in comparison to OSA alone. Even after adjustment for confounding variables, the level of oxidative stress (measured by urinary 8-isoprostanes) is significantly higher in the overlap syndrome compared to OSA alone. One month treatment with BiPAP improved the ventilatory and gas exchange parameters and decreased the oxidative stress level in overlap patients. Despite the lack of weight reduction, a significant improvement in glucometabolic parameters was established. 


\section{Future directions}

The new definitions of OSA proposed by the American Association of Sleep Medicine (AASM), based on epidemiological data sets are a major change of perspective that may facilitate the diagnostic approach to overlap [92]. The data regarding the prevalence of OSA in the general population and in COPD must be re-analysed. This is especially important to reestablish clinical phenotypes of both diseases in order to acquaint clinicians with the signs and symptoms that are highly suggestive of OSA in mild/moderate COPD and those suggestive of COPD in OSA patients.

'Molecular" and "physiological" studies are needed to evaluate the role of oxidative stress and inflammation in overlap syndrome as well as its possible additive and/or synergistic effects on cardiovascular morbidity. Biomarkers, indicative of increased cardiovascular risk are also demanded.

The introduction of more standardized therapeutic approaches is mandatory. The effects of oxygen therapy in COPD patients with only nighttime hypoxaemia and/or mild daytime hypoxaemia are unknown, especially those regarding gas exchange and pulmonary haemodynamics outcomes.

Overlap patients have severe daytime hypoxaemia than is expected based on lung mechanics. The effect of CPAP on dayime hypoxaemia in overlap syndrome has not, however, been investigated. It is obvious from the study of Machado et al, that some indications for LTOT should be reconsidered in a group of overlap patients; follow-up visits and reevaluation of ventilatory therapy should also be performed in detail. CPAP is the first choice in a phenotype of overlap patients where "OSA is prevalent". The optimal therapy for patients with mild OSA and moderate/severe COPD or for those with mild OSA and COPD remains a challenge.

It is obvious that CPAP is not as safe in COPD as is generally supposed. Holanda et al stated that in COPD, CPAP increased lung volume and worsened the baseline level of alveolar hyperinflation [189]. The AASM has proposed non-invasive ventilation for treatment of patients with overlap syndrome, especially for those intolerant of CPAP, or those with severe nocturnal hypoxia and/or hypoventilation. Pressure support ventilation stabilizes the upper airways in patients with OSA or overlap, as it changes the level of effective pressure between inspiration and expiration. It is also the most common mode of ventilation for the management of COPD related nocturnal hypoventilation.

Comparative follow-up mortality studies in overlap patients treated with either CPAP or BiPAP modality are required to determine the optimal therapeutic management.

\section{Author details}

Radostina Vlaeva Cherneva ${ }^{1 *}$, Ognian Borisov Georgiev ${ }^{1}$, Daniela Stoichkova Petrova ${ }^{1}$, Emil Ivanov Manov ${ }^{2}$ and Julia Ivanova Petrova ${ }^{3}$ 
*Address all correspondence to: cherneva_radost@yahoo.com

1 Department of Internal Medicine, Division of Pulmonary Medicine, Medical University, Sofia, Bulgaria

2 Department of Internal Medicine, Division of Cardiology, Medical University, Sofia, Bulgaria

3 Department of Neurology, Medical University, Sofia, Bulgaria

\section{References}

[1] Douglas NJ, White DP, Pickett CK, et al.Respiration during sleep in normal man. Thorax,1982a; 37:840-4.

[2] White DP, Weil JV, Zwillich CW. Matabolic rate and breathing during sleep. J Appl. Physio 1985;58:384-91.

[3] Morrel MJ, Harty HR, Adams L, et al. Changes in total pulmonary resistance and PCO2 between wakefulness and slepp in normal human subjects. J Appl. Physiol. 1995;78:1339-49.

[4] Douglas NJ, White DP, Weil JV, et al. Hypercapnic ventilatory response in sleeping adults. Am. Rev Respir Dis 1982:126:758-62.

[5] Becker HF, Piper AJ, Flynn WE, et al. Breathing during sleep in patients with nocturnal desaturation. Am J Resp Crit Care Med 1999;159:112-8

[6] Calverley PM, Brezinova V, Douglas NJ, et al. The effect of oxygenation on sleep quality in hronic bronchitis and amphysema. Am Rev Resp Dis. 1982;126:206-10.

[7] Wiegand DA, Latz B, Zwillich CW, et al. Geniohyoid muscle activity in normal men during wakefulness and sleep. J Appl. Physiol 1990;60:1262-9.

[8] Basner RC, Ringler J, Schawartzstein RM, et al. Phasic electromyographic activity of the genioglossus increases in normals during slow wave sleep.Respir Physiol, 1991;83:189-200.

[9] Tangel DJ, Mezzanotte WS, Sandberg EJ, et al. Influences of NREM sleep on the activity of tonic vs. inspiratory phasic muscles in normal men.J Appl Phisiol 1992; 73:1058-66.

[10] Ballard RD, Clover CW, Suh BY. Influence of sleep on respiratory function in emphysema. Am J Resp Crit Care Med 1995;151:945-51.

[11] Hudgel DW, Dewadatta P. Decrease in functional residual capacity in normal humans. J Appl Physiol 1984;57:1319-22. 
[12] Bryan AC, Muller NL. Lung mechanucs and gas exchange during sleep.Sleep 1980; 3:401-6.

[13] Block AJ, Boysen PG, Wynne JW, et al. Sleep apnea, hypopnea and oxygen desaturation in normal subjects. A strong male predominance. N Engl J Med 1979;300:513-7.

[14] Trask CH, Cree EM. Oximeter studies on patients with chronic obstructive emphysema, awake and during sleep. N Engl J Med. 1962; 266:639-642.

[15] Pierce AK, Jarrett CE, Werkle G Jr, Miller WF. Respiratory function during sleep in patients with chronic obstructive lung disease. J Clin Invest. 1966; 45(5):631-636.

[16] Chaouat A, Weitzenblum E, Kessler R, Charpentier C, Ehrhart M, Levi-Valensi P, et al. Sleep related $\mathrm{O} 2$ desaturation and daytime pulmonary haemodynamics in COPD patients with mild hypoxaemia. Eur Respir J. 1997; 10(8):1730-1735.

[17] Fletcher EC, Schaaf JW, Miller J, Fletcher JG. Long-term cardio-pulmonary sequelae in patients with sleep apnea and chronic lung disease. Am Rev Respir Dis. 1987; 135(3):525-533.

[18] Lewis CA, Fergusson W, Eaton T, Zeng I, Kolbe J. Isolated nocturnal desaturation in COPD: prevalence and impact on quality of life and sleep. Thorax. 2009; 64(2):133138.

[19] Ramar K. Sleep Problems in Chronic Obstructive Pulmonary Disease. Tur Toraks Der 2008;9:117-23.

[20] Wynne JW, Block AJ, Hemenway J, et al. Disordered breathing and oxygen desaturation during sleep in patients with chronic obstructive lung disease (COLD). Am J Med 1979;66:573-9.

[21] Catterall JR, Douglas NJ, Calverley PM, et al. Transienthypoxemia during sleep in chronic obstructive pulmonary disease is not a sleep apnea syndrome. Am Rev Respir Dis 1983;128:24-9.

[22] Catterall JR, Calverley PM, MacNee W, et al.Mechanism of transient nocturnal hypoxemia in hypoxic chronic bronchitis and emphysema. J Appl Physiol, 1985;59:1698703.

[23] Lewis CA, Eaton TE, Fergusson W, et al. Home overnight pulse oximetry in patients with COPD: more than one recording may be needed. Chest,2003;123:1127-33.

[24] Mulloy E, McNicholas WT.Ventilation and gas exchange during sleep and exercise in severe COPD. Chest,1996; 109:387-94.

[25] Flenley DC.Sleep in chronic obstructive lung disease. Clin Chest Med,1985;6:651-61.

[26] O'Donoghue FJ, Catcheside PG, Eckert DJ, McEvoy RD. Changes in respiration in NREM sleep in hypercapnic chronic obstructive pulmonary disease. J Physiol 2004;559:663-73. 
[27] Pronzato C. Chronic Obstructive Pulmonary disease and obstructive sleep apnea. Association, consequences and treatment.Monaldi Arch Chest Dis,2010;73:155-161.

[28] Bonsignore MR, Marrone O, Insalaco G, et al. The cardiovascular effects of obstructive sleep apnoeas: analysis of pathogenic mechanisms. Eur Respir J, 1994;7:786-805.

[29] Coccagna G, Lugaresi E. Arterial blood gases and pulmonary and systemic arterial pressure during sleep in chronic obstructive pulmonary disease. Sleep 1978;1:117-24.

[30] Weitzenblum E, Chaouat A. Sleep and chronic obstructive pulmonary disease. Sleep Med Rev, 2004;8:281-94.

[31] Boysen PG, Block AJ, Wynne JW, et al. Nocturnal pulmonary hypertension in patients with chronic obstructive pulmonary disease. Chest 1979;76:536-42.

[32] Fletcher EC, Levin DC. Cardiopulmonary hemodynamics during sleep in subjects with chronic obstructive pulmonary disease. The effect of short-and long-term oxygen. Chest 1984;85:6-14.

[33] Weitzenblum E, Muzet A, Ehrhart M, et al. Nocturnal changes in blood gases and pulmonary arterial pressure in chronic bronchitis patients with respiratory insufficiency. Nouv Presse Med 1982;11:1119-22.

[34] Fletcher EC, Luckett RA, Miller T, et al. Pulmonary vascular hemodynamics in chronic lung disease patients with and without oxyhemoglobin desaturation during sleep. Chest 1989;95:757-64.

[35] Levi-Valensi P, Weitzenblum E, Rida Z, et al. Sleep-related oxygen desaturation and daytime pulmonary haemodynamics in COPD patients. Eur Respir J 1992;5:301-7.

[36] Wright JL, Levy RD, Churg A. Pulmonary hypertension in chronic obstructive pulmonary disease: current theories of pathogenesis and their implications for treatment. Thorax, 2005;60:605-9.

[37] Sajkov D, McEvoy RD. Obstructive sleep apnea and pulmonary hypertension. Prog Cardiovasc Dis. 2009; 51(5):363-370.

[38] Chaouat A, Weitzenblum E, Kessler R, Charpentier C, Enhart M, Schott R, et al. A randomized trial of nocturnal oxygen therapy in chronic obstructive pulmonary disease patients. Eur Respir J. 1999; 14(5):1002-1008.

[39] McNicholas WT, Fitzgerald MX. Nocturnal deaths among patients with chronic bronchitis and emphysema. BMJ (Clin Res Ed). 1984; 289(6449):878.

[40] Flick MR, Block AJ. Nocturnal vs diurnal cardiac arrhythmias in patients with chronic obstructive pulmonary disease. Chest 1979;75:8-11.

[41] Shepard JW Jr., Schweitzer PK, Keller CA, et al. Myocardial stress. Exercise versus sleep in patients with COPD. Chest 1984;86:366-74 
[42] Fletcher EC, Miller J, Divine GW, et al. Nocturnal oxyhemoglobin desaturation in COPD patients with arterial oxygen tensions above $60 \mathrm{~mm} \mathrm{Hg}$. Chest 1987;92:604-8.

[43] Fitzpatrick MF, Mackay T, Whyte KF, et al. Nocturnal desaturation and serum erythropoietin: a study in patients with chronic obstructive pulmonary disease and in normal subjects. Clin Sci (Lond) 1993;84:319-24.

[44] Cormick W, Olson LG, Hensley MJ, Saunders NA. Nocturnal hypoxaemia and quality of sleep in patients with chronic obstructive lung disease. Thorax. 1986; 41(11): 846-854

[45] Sin DD, Man SF. Chronic obstructive pulmonary disease: a novel risk factor for cardiovascular disease. Can J Physiol Pharmacol. 2005; 83(1):8-13.

[46] Connaughton JJ, Catterall JR, Elton RA, et al. Do sleep studies contribute to the management of patients with severe chronic obstructive pulmonary disease? Am Rev Respir Dis 1988;138:341-4.

[47] Marin JM, Soriano JB, Carrizo SJ, Boldova A, Celli BR. Outcomes in patients with chronic obstructive pulmonary disease and obstructive sleep apnea: the overlap syndrome. Am J Respir Crit Care Med. 2010; 182(3):325-33

[48] Donaldson GC, Seemungal TA, Bhowmik A, Wedzicha JA. Relationship between exacerbation frequency and lung function decline in chronic obstructive pulmonary disease. Thorax. 2002; 57(10):847-852.

[49] Soler-Cataluna JJ, Martinez-Garcia MA, Roman Sanchez P, Salcedo E, Navarro M, Ochando R. Severe acute exacerbations and mortality in patients with chronic obstructive pulmonary disease. Thorax. 2005; 60(11):925-931.

[50] Bellia V, Catalano F, Scichilone N, et al. Sleep disorders in theelderly with and without chronic airfl ow obstruction: the SARA study.Sleep, 2003;26:318-23.

[51] Klink M, Quan SF. Prevalence of reported sleep disturbancesin a general adult population and their relationship toobstructive airways diseases. Chest 1987;91:540-6

[52] Kinsman RA, Yaroush RA, Fernandez E, Dirks JF, Schocket M, Fukuhara J. Symptoms and experiences in chronic bronchitis and emphysema. Chest. 1983; 83(5):755761.

[53] Klink ME, Dodge R, Quan SF. The relation of sleep complaints to respiratory symptoms in a general population. Chest. 1994; 105(1):151-154.

[54] Krachman SL, Chatila W, Martin UJ, et al. Effects of lungvolume reduction surgery on sleep quality and nocturnal gasexchange in patients with severe emphysema. Chest, 2005;128:3221-8.

[55] Sanders MH, Newman AB, Haggerty CL, et al. Sleep and sleep-disordered breathing in adults with predominantlymild obstructive airway disease. Am J Respir Crit Care Med 2003;167:7-14. 
[56] Redline S, Kirchner HL, Quan SF, et al. The effects of age, sex, ethnicity, and sleepdisordered breathing on sleep architecture. Arch Intern Med, 2004;164:406-18.

[57] Fleetham J, West P, Mezon B, et al. Sleep, arousals, and oxygen desaturation in chronic obstructive pulmonary disease. The effect of oxygen therapy. Am Rev Respir Dis 1982;126:429-33.

[58] Sandek K, Andersson T, Bratel T, et al.Sleep quality, carbon dioxide responsiveness and hypoxaemic patterns in nocturnal hypoxaemia due to chronic obstructive pulmonary disease (COPD) without daytime hypoxaemia. Respir Med, 1999;93:79-87.

[59] Orr WC, Shamma-Othman Z, Levin D, et al. Persistent hypoxemia and excessive daytime sleepiness in chronic obstructive pulmonary disease (COPD). Chest 1990;97:583-5.

[60] DeMarco FJ Jr., Wynne JW, Block AJ, et al. Oxygen desaturation during sleep as a determinant of the "Blue and Bloated" syndrome. Chest 1981;79:621-5.

[61] Bradley TD, Mateika J, Li D, et al. Daytime hypercapnia in the development of nocturnal hypoxemia in COPD. Chest 1990;97:308-12.

[62] Mulloy E, Fitzpatrick M, Bourke S, O'Regan A, McNicholas WT. Oxygen desaturation during sleep and exercise in patients with severe chronic obstructive pulmonary disease. Respir Med. 1995; 89(3):193-198.

[63] Krachman S, Minai OA, Scharf SM. Sleep abnormalities and treatment in emphysema. Proc Am Thorac Soc. 2008; 5(4):536-542

[64] Celli BR, MacNee W; ATS/ERS Task Force. 2004. Standards for the diagnosis and treatment of patients with COPD: a summary of the ATS/ERS position paper. Eur Respir J, 2004;23:932-46.

[65] Hiestand DM, Britz P, Goldman M, et al. Prevalence of symptoms and risk of sleep apnea in the US population: Results from the national sleep foundation sleep in America 2005 Chest, 2006; 130:780-6.

[66] Carratu P and Resta O. Is obstructive sleep apnea a comorbidity of COPD and is it involved in systemic inflammatory syndrome? ERJ, 2008:31:1381-1382.

[67] Wiegand L, Zwillich CW.. Obstructive sleep apnea. Dis Mon, 1994;40:197-252

[68] Fogel RB, Malhotra A, White DP. Sleep. 2: pathophysiology of obstructive sleep apnoea/hypopnoea syndrome. Thorax, 2004;59:159-63.

[69] Liistro G. Pathophysiology of upper airway obstruction during sleep. Acta Otorhinolaryngol Belg,. 2002;56:101-6.

[70] Hudgel DW, Gordon EA, Thanakitcharu S, et al. Instability of ventilatory control in patients with obstructive sleep apnea. Am J Respir Crit Care Med, 1998;158:1142-9. 
[71] Younes M, Ostrowski M, Thompson W, et al.. Chemical control stability in patients with obstructive sleep apnea. Am J Respir Crit Care Med, 2001;163:1181-90.

[72] Series F, Cormier Y, Desmeules M, et al. Effects of respiratory drive on upper airways in sleep apnea patients and normal subjects. J Appl Physiol, 1989; 67:973-9.

[73] Garay SM, Rapoport D, Sorkin B, et al.. Regulation of ventilation in the obstructive sleep apnea syndrome. Am Rev Respir Dis, 1981;124:451-7.

[74] Soto Campos JG, Cano GS, Fernandez GJ, et al.. Hypercapnic stimulation and ventilation response in the syndrome of sleep obstructive apnea. Comparison of reinhalation and steady state. Arch Bronconeumol, 1996;32:341-7.

[75] El Bayadi S, Millman RP, Tishler PV, et al.. A family study of sleep apnea. Anatomic and physiologic interactions. Chest, 1990;98:554-9.

[76] Redline S, Leitner J, Arnold J, et al.. Ventilatory-control abnormalities in familial sleep apnea. Am J Respir Crit Care Med, 1997;156:155-60.

[77] Berthon-Jones M, Sullivan CE. Time course of change in ventilatory response to CO2 with long-term CPAP therapy for obstructive sleep apnea. Am Rev Respir Dis, 1987;135:144-7.

[78] Lin CC.Effect of nasal CPAP on ventilatory drive in normocapnic and hypercapnic patients with obstructive sleep apnoea syndrome. Eur Respir J, 1994;7:2005-10.

[79] Redolfi S, Yumino D, Ruttanaumpawn P, et al. Relationship between overnight rostral fluid shift and obstructive sleep apnea in non-obese men. Am j respire Crit Care Med 2009;179:241-246.

[80] Eckert DJ, Saboisky JP, Jordan AS, Malhotra A. Upper airway myopathy is not important in the pathophysiology of obstructive sleep apnea. J Clin Sleep Med. 2007; 3(6):570-573.

[81] Owens RL, Malhotra A, Eckert DJ, White DP, Jordan AS. The influence of end-expiratory lungvolume on measurements of pharyngeal collapsibility. J Appl Physiol. 2010; 108(2):445-451.

[82] Nadel JA, Widdicombe JG. Reflex effects of upper airway irritation on total lung resistance andblood pressure. J Appl Physiol. 1962; 17:861-865.

[83] Owens RL, Malhtora A. Sleep-Disordered Breathing and COPD: The Overlap Syndrome Respir Care. 2010;55(10): 1333-1346.

[84] De Miguel J, Cabello J, Sanchez-Alarcos JM, et al. Long-term effects of treatment with nasal continuous positive airway pressure on lung function in patients with overlap syndrome. Sleep Breath, 2002.;6:3-10.

[85] Young T, Palta M, Dempsey J, et al. The occurrence of sleepdisordered breathing among middle-aged adults. N Engl J Med, 1993;328:1230-5. 
[86] Guilleminault C. Obstructive sleep apnea. The clinical syndrome and historical perspective. Med Clin North Am, 1985;69:1187-203.

[87] Chaouat A, Weitzenblum E, Krieger J, et al.. Association of chronic obstructive pulmonary disease and sleep apnea syndrome. Am J Respir Crit Care Med, 1995;151:82-6.

[88] Lopez-Acevedo MN, Torres-Palacios A, Elena Ocasio-Tascon M, Campos-Santiago Z, Rodriguez-

[89] tron W. Overlap syndrome: an indication for sleep studies?: a pilot study. Sleep Breath. 2009; 13(4):409-413.

[90] Bednarek M, Plywaczewski R, Jonczak L, Zielinski J. There is no relationship between chronic obstructive pulmonary disease and obstructive sleep apnea syndrome: a population study. Respiration. 2005; 72(2):142-149.

[91] Iber C, Ancoli-Israel S, Chesson AL, Quan SF. Thea AASM manual for the scoring of sleep and associated events. Rules, terminology, and technical specifications. Westchester, III, Illinois: American Academy of Sleep Medicine, 2007.

[92] The Global strategy for the diagnosis, management and prevention of COPD, 2011

[93] Guilleminault C, Tilkian A, Dement WC. The sleep apnea syndromes. Ann Rev Med, 1976;27:465-84.

[94] Leech JA, Onal E, Baer P, et al. Determinants of hypercapnia in occlusive sleep apnea syndrome. Chest, 1987;92:807-13.

[95] Chan CS, Bye PTP, Woolclock AJ, Sullivan Ce. Eucapnia and hypercapnia in patients with chronic airflow limitation. The role of upper airways. Am Rev Respir Dis 1990;141:861-865.

[96] Radwan L, Maszczyk Z, Koziorowski A, Koziej M, Cieslicki J, Sliwinski P, Zielinski J. Control of breathing in obstructive sleep apnoea and in patients with the overlap syndrome. Eur Respir J. 1995; 8(4):542-545.

[97] Chien MY, Wu YT, Lee Pl, Chang YJ, Yang PC. Inspiratory muscle dysfunction in patients with severe obstructive sleep apnea. Eur Respir J 2010;35:373-80.

[98] Yee BJ, Cheung J, Phipps P, Banerjee D, Piper AJ, Grunstein RR. Treatment of obesity hypoventilation syndrome and serum leptin. Respiration. 2006; 73(2):209-212.

[99] Sanner BM, Doberauer C, Konermann M, et al.. Pulmonary hypertension in patients with obstructive sleep apnea syndrome. Arch Intern Med, 1997;157:2483-7.

[100] Bady E, Achkar A, Pascal S, et alPulmonary arterial hypertension in patients with sleep apnoea syndrome. Thorax, 2000;55:934-9.

[101] Sajkov D, Wang T, Saunders NA, et al. Daytime pulmonary hemodynamics in patients with obstructive sleep apnea without lung disease. Am J Respir Crit Care Med, 1999;159:1518-26. 
[102] Laks L, Lehrhaft B, Grunstein RR, et al. Pulmonary hypertension in obstructive sleep apnoea. Eur Respir J, 1995;8:537-41.

[103] Bradley TD.. Right and left ventricular functional impairment and sleep apnea. Clin Chest Med, 1992;13:459-79.

[104] Hawrylkiewicz I, Sliwinski P, Gorecka D, Plywaczewski R, Zielinski J. Pulmonary haemodynamics in patients with OSAS or an overlap syndrome. Monaldi Arch Chest Dis. 2004;61(3):148-152.

[105] Arias MA, Garcia-Rio F, Alonso-Fernandez A, Martinez I, Villamor J. Pulmonary hypertension in obstructive sleep apnoea: effects of continuous positive airway pressure: a randomized, controlled cross-over study. Eur Heart J. 2006; 27(9):1106-1113.

[106] Gami AS, Howard DE, Olson EJ, Somers VK. Day-night pattern of sudden death in obstructive sleep apnea. N Engl J Med. 2005; 352(12):1206-1214.

[107] Olmetti F, La Rovere MT, Robbi E, et al. Nocturnal cardiac arrhythmia in patients with obstructive sleep apnea. Sleep Med, 2008, 9:475-80.

[108] Chaouat A, Weitzenblum E, Krieger J, Krieger J, Sforza E, Hammad H, Oswald M, Kessler R. Prognostic value of lung function and pulmonary haemodynamics in OSA patients treated with CPAP. Eur Respir J. 1999; 13(5):1091-1096.

[109] Lavie P, Herer P, Lavie L. Mortality risk factors in sleep apnoea: a matched case-control study. J Sleep Res. 2007; 16(1):128-134.

[110] Lavie P, Herer P, Peled R, Berger I, Yoffe N, Zomer J, Rubin AH. Mortality in sleep apnea patients: a multivariate analysis of risk factors. Sleep. 1995; 18(3):149-157.

[111] Mermigkis C, Kopanakis A, Foldvary-Schaefer N, Golish J, Polychronopoulos V, Schiza S, et al. Health-related quality of life in patients with obstructive sleep apnoea and chronic obstructive pulmonary disease (overlap syndrome). Int J Clin Pract. 2007; 61(2):207-211.

[112] Ross R. Atherosclerosis--an infl ammatory disease. N Engl J Med, 1999;340:115-26.

[113] Hansson GK.Inflammation, atherosclerosis, and coronary artery disease. N Engl J Med, 2005;352:1685-95

[114] Agusti AG, Noguera A, Sauleda J, et al.. Systemic effects of chronic obstructive pulmonary disease. Eur Respir J, 2003;21:347-60.

[115] Yende S, Waterer GW, Tolley EA, et al. Infl ammatory markers are associated with ventilatory limitation and muscle dysfunction in obstructive lung disease in well functioning elderly subjects. Thorax, 2006; 61:10-6.

[116] Camilli AE, Robbins DR, Lebowitz MD. Death certifi cate reporting of confirmed airways obstructive disease. Am J Epidemiol, 1991;133:795-800. 
[117] Sin DD, Man SF.Why are patients with chronic obstructive pulmonary disease at increased risk of cardiovascular diseases? The potential role of systemic infl ammation in chronic obstructive pulmonary disease. Circulation, 2003;107:1514-9.

[118] Nieto FJ, Herrington DM, Redline S, et alSleep apnea and markers of vascular endothelial function in a large community sample of older adults. Am J Respir Crit Care Med,. 2004;169:354-60.

[119] Jelic S, Bartels MN, Mateika JH, et al. Arterial stiffness increases during obstructive sleep apneas. Sleep, 2002;25:850-5.

[120] RidkerPM,Cushman M, Stamfer MJ,Tracy RP,Henekenes Ch. Inflammation, aspirin, and the risk of cardiovascular disease in apparently healthy men. N Engl. J Med, 1997;336:973-979.

[121] Yokoe T, Mingouchi K, Matsuo H et al. Elevated levels of C-reactive protein and IL-6 in patients with OSA are decreased after nasal continuous positive airway pressure. Circulation 2003;107:1129-34.

[122] Mehra R, Strfofer -Isser A, Kirchner HL, et al. Soluble IL-6 receptor: a marker of moderate to severe sleep related brething disorders.Arch intern Med 2006;166:1725-31.

[123] Man SF, Connett JE, Anthonisen NR, et al. C-reactive protein and mortality in mild to moderate chronic obstructive pulmonary disease. Thorax, 2006;61:849-53.

[124] Pinto-Plata VM, Mullerova H, Toso JF, et al. C-reactive protein in patients with COPD, control smokers and non-smokers. Thorax, 2006;61:23-8.

[125] Zamarron-Sanz C, Ricoy-Galbaldon J, Gude-Sampedro F, et al. Plasma levels of vascular endothelial markers in obstructive sleep apnea. Arch Med Res, 2006;37:552-5

[126] Ryan S, Taylor CT, McNicholas WT, et al. Slective activation of inflammatory pathways by intermittent hypoxia in OSA. Circulation 2005;112:2660-2667.

[127] Ryan S, Taylor CT, McNicholas WT, et al. Predictors of elevated NF-kB dependent genes in OSA. Am J Resp Crit Care Med,2006:174:824-830.

[128] Cesari M, Pennix BWJH, Newman AB, et al. Inflammatory markers and onset of cardiovascular events: results from the Health ABC Study. Circulation, 2003;108:2317-22.

[129] MacNee W. Oxidants/antioxidants and COPD. Chest 2000;117:303-317.

[130] Lavie L. Obstructive sleep apnea syndrome-an oxidative stress disorder. Sleep Med Rev 2003;7:35-51.

[131] Schulz R, Mahmoudi S, Hattar K et al. Enhanced release of superoxide from polymorphonuclear neutrophils in obstructive sleep apnea : impact oof continuous positive airway pressure therapy. Am J Respir Crit Care Med 2000;162:566-570. 
[132] Droge W. Free radicals in the physiological control of cell function. Physiol Rev 2002;82:47-95.

[133] Gan WQ, Man SFP, Senthilselvan A, Sin DD. Association between chronic obstructive pulmonary disease and systemic inflammation : a systemic review and a metaanalysis. Thorax, 2004;59:574-80.

[134] Dyuogovskaya L, Polyakov A, lavie P, Lavie L. Delayed neutrophil apoptosis in patients with sleep apnea. Am J respire Crit Care med. 2008;177:544-554.

[135] Nieto FJ, Young TB,Lind BK, et al.Association of sleep disordered breathing, sleep apnea, and hypertension in a large community-based study Sleep Heart Health Study. JAMA, 2000;283:1829-36.

[136] Peppard PE, Young T, Palta M et al. Prospective study of the association between sleep disordered breathing and hypertension. N Engl J Med 2000;342:1378-84.

[137] Gottlieb DJ, Yenokyan G, Newman AB, et al.Prospective study of obstructive sleep apnea and incident coronary heart disease and heart failure. Circulation, 2010;122:352-360.

[138] Redline S, Yenokyan G, Gottlieb DJ, et al. Obstructive sleep apnea and hypopnea and incident stroke. Am J Respir Crit Care Med 2010;182:269-277.

[139] Peker Y, Hadner J, Kraiczi H, et al. Respiratory disturbamce index an independent predictor of mortality in coronary heart disease. Am J Respir Crit Care Med 2000;162:81-86.

[140] Drager LF, Bortolotto LA, Lorenzi MC, et al.Early signs of atherosclerosis in obstructive sleep apnea Am J Respir Crit Care Med 2005;172:613-618.

[141] Nieto FJ,Peppard PE, Young TB. Sleep disordered breathing and the meatobolic syndrome. WMJ 2009;108:263-265

[142] Wolk R, Somers VK. Sleep and metabolic syndrome. Exp Physiol 2007;92:67-78.

[143] Colt HG, Haas H, Rich GB. Hypoxemia vs sleep fragmentation as cause of excessive daytime sleepiness in obstructive sleep apnea. Chest, 1991;100:1542-8

[144] Seneviratne U, Puvanendran K. Excessive daytime sleepiness in obstructive sleep apnea: prevalence, severity, and predictors. Sleep Med, 2004;5:339-43.

[145] Saaresranta T, Irjala K, Aittokallio T, et al. Sleep quality, daytime sleepiness and fasting insulin levels in women with chronic obstructive pulmonary disease. Respir Med, 2005;99:856-63.

[146] Zamarron C, Gude F, Otero Y, et al. Symptoms of sleep apnea syndrome in the general population. Arch Bronconeumol, 1998;34:245-9. 
[147] Pichel F, Zamarron C, Magan F, et al. Health-related quality of life in patients with obstructive sleep apnea: effects of long-term positive airway pressure treatment. Respir Med, 2004;98:968-76.

[148] O'Brien A, Whitman K. Lack of benefi $t$ of continuous positive airway pressure on lung function in patients with overlap syndrome. Lung, 2005;183:389-404.

[149] Resta O, Foschino-Barbaro MP, Bonfi tto P, et al.. Prevalence and mechanisms of diurnal hypercapnia in a sample of morbidly obese subjects with obstructive sleep apnoea. Respir Med, 2000;94:240-6.

[150] Kessler R, Chaouat A, Weitzenblum E, et al.Pulmonary hypertension in the obstructive sleep apnoea syndrome: prevalence, causes and therapeutic consequences. Eur Respir J, 1996;9:787-94.

[151] Marin JM, Carrizo SJ, Vicente E, et al. Long-term cardiovascular outcomes in men with obstructive sleep apnoea-hypopnoea with or without treatment with continuous positive airway pressure: an observational study. Lancet,. 2005;365:1046-53.

[152] Bradley JM, Lasserson T, Elborn S, et al. A systematic review of randomized controlled trials examining the short-term benefit of ambulatory oxygen in COPD. Chest. 2007 Jan;131(1):278-85.

[153] Laaban JP, Chailleux E.. Daytime hypercapnia in adult patients with obstructive sleep apnea syndrome in France, before initiating nocturnal nasal continuous positive airway pressure therapy. Chest, 2005;127:710-15.

[154] Martin RJ, Bartelson BL, Smith P, et al. Effect of ipratropium bromide treatment on oxygen saturation and sleep quality in COPD. Chest 1999;115:1338-45.

[155] McNicholas WT, Calverley PM, Lee A, Edwards JC. Long-acting inhaled anticholinergic therapy improves sleeping oxygen saturation in COPD. Eur Respir J 2004;23:825-31.

[156] Mulloy E, McNicholas WT. Theophylline improves gas exchange during rest, exercise, and sleep in severe chronic obstructive pulmonary disease. Am Rev Respir Dis 1993;148:1030-6.

[157] Berry RB, Desa MM, Branum JP, Light RW. Effect of theophylline on sleep and sleepdisordered breathing in patients with chronic obstructive pulmonary disease. Am Rev Respir Dis 1991;143:245-50.

[158] Man GC, Champman KR, Ali SH, Darke AC. Sleep quality and nocturnal respiratory function with once-daily theophylline (Uniphyl) and inhaled salbutamol in patients with COPD. Chest 1996;110:648-53.

[159] Martin RJ, Pak J. Overnight theophylline concentrations and effects on sleep and lung function in chronic obstructive pulmonary disease. Am Rev Respir Dis 1992;145:540-4. 
[160] Block AJ, Dolly FR, Slayton PC. Does flurazepam ingestion affect breathing and oxygenation during sleep in patients with chronic obstructive lung disease? Am Rev Respir Dis 1984;129:230-3.

[161] Girault C, Muir JF, Mihaltan F, et al. Effects of repeated administration of zolpidem on sleep, diurnal and nocturnal respiratory function, vigilance, and physical performance in patients with COPD. Chest 1996;110:1203-11.

[162] Ryan S, Doherty LS, Rock C, Nolan GM, McNicholas WT. Effects of salmeterol on sleepingoxygen saturation in chronic obstructive pulmonary disease. Respiration. 2010;79:475-81.

[163] Sposato B, Mariotta S, Palmiero G, Ricci A, Gencarelli G, Franco C. Oral corticosteroids can improve nocturnal isolated hypoxemia in stable COPD patients with diurnal PaO2 > 60 mmHg. Eur Rev Med Pharmacol Sci. 2007; 11(6):365-372.

[164] Weitzenblum E, Chaouat A, Charpentier C, et al. Sleep-related hypoxaemia in chronic obstructive pulmonary disease: causes, consequences and treatment. Respiration, 1997;64:187-93.

[165] Nocturnal Oxygen Therapy Trial Group. Continuous or nocturnal oxygen therapy in hypoxemic chronic obstructive lung disease: a clinical trial. Ann Intern Med. 1980; 93(3):391-398.

[166] Report of the Medical Research Council Working Party. Long term domiciliary oxygen therapy inchronic hypoxic cor pulmonale complicating chronic bronchitis and emphysema. Lancet. 1981; 1(8222):681-686.

[167] Fletcher EC, Donner CF, Midgren B, zielinski J, Levi-Valensi P, Braghiroli A, et al. Survival in COPD patients with a daytime $\mathrm{PaO} 2$ greater than $60 \mathrm{~mm} \mathrm{Hg}$ with and without nocturnal oxyhemoglobin desaturation. Chest. 1992; 101(3):649-655.

[168] Gorecka D, Gorzelak K, Sliwinski P, et al. Effect of long-term oxygen therapy on survival in patients with chronic obstructive pulmonary disease with moderate hypoxaemia.Thorax 1997;52:674-9.

[169] Fletcher EC, Luckett RA, Goodnight-White S, et al. A double-blind trial of nocturnal supplemental oxygen for sleep desaturation in patients with chronic obstructive pulmonary disease and a daytime $\mathrm{PaO} 2$ above $60 \mathrm{~mm} \mathrm{Hg}$. Am Rev Respir Dis 1992;145:1070-6.

[170] Kolodziej MA, Jensen L, Rowe B, Sin D. Systematic review of noninvasive positive pressure ventilation in severe stable COPD. Eur Respir J 2007;30:293-306.

[171] Clinical indications for noninvasive positive pressure ventilation in chronic respiratory failure due to restrictive lung disease, COPD, and nocturnal hypoventilation--a consensus conference report. Chest 1999;116:521-34. 
[172] McEvoy RD, Pierce RJ, Hillman D, Esterman A, Ellis EE, Catcheside PG, et al. Nocturnal noninvasive nasal ventilation in stable hyper-capnic COPD: a randomised controlled trial. Thorax. 2009; 64(7):561-566.

[173] Windisch W, Haenel M, Storre JH, Dreher M. High-intensity non-invasive positive pressure ventilation for stable hypercapnic COPD. Int J Med Sci. 2009; 6(2):72-76.

[174] Giles TL, Lasserson TJ, Smith BJ, et al. Continuous positive airways pressure for obstructive sleep apnoea in adults. Cochrane Database Syst Rev, 2006.

[175] Marshall NS, Barnes M, Travier N, et al. Continuous positive airway pressure reduces daytime sleepiness in mild to moderate obstructive sleep apnoea: a meta-analysis. Thorax, 2006;61:430-4.

[176] Haynes PL.. The role of behavioral sleep medicine in the assessment and treatment of sleep disordered breathing. Clin Psychol Rev, 2005;25:673-705.

[177] Morgenthaler TI, Kapen S, Lee-Chiong T, Alessi C, Boehlecke B, Brown T, et al. Practice parameters for the medical therapy of obstructive sleep apnea. Sleep. 2006; 29(8): 1031-1035.

[178] Sampol G, Sagales MT, Roca A, de la Calzada MD, Bofill JM, Morell F. Nasal continuous positive airway pressure with supplemental oxygen in coexistent sleep apnoeahypopnoea syndrome and severe chronic obstructive pulmonary disease. Eur Respir J. 1996; 9(1):111-116

[179] Costa D, Toledo A, Silva AB, et al. Influence of noninvasive ventilation on exercise tolerance and respiratory muscle strength in COPD patients.Rev Lationo-am Enfermagem, 2006;14:378-82.

[180] Mezzanotte WS, Tangel DJ, Fox AM, Ballard RD, White DP. Nocturnal nasal continuous positive airway pressure in patients with chronic obstructive pulmonary disease: influence on waking respiratory muscle function. Chest. 1994; 106(4):1100-1108

[181] Mansfield D, Naughton MT. Effects of continuous positive airway pressure on lung function in patients with chronic obstructive pulmonary disease and sleep disordered breathing. Respirology. 1999; 4(4):365-370.

[182] Sforza E, Krieger J, Weitzenblum E, Apprill M, Lampert E, Ratamaharo J. Long-term effects of treatment with nasal continuous positive airway pressure on daytime lung function and pulmonary hemodynamics in patients with obstructive sleep apnea. Am Rev Respir Dis. 1990; 141(4 Pt 1): 866-870.

[183] Peker Y, Hedner J, Johansson A, Bende M. Reduced hospitalization with cardiovascular and pulmonary disease in obstructive sleep apnea patients on nasal CPAP treatment. Sleep. 1997; 20(8):645-653. 
[184] Campos-Rodriguez F, Perez-Ronchel J, Grilo-Reina A, et al. Longterm effect of continuous positive airway pressure on BP in patients with hypertension and sleep apnea Chest, 2007;132:1847-52.

[185] Machado MC, Vollmer WM, Togeiro SM, Bilderback AL, Oliveira MV, Leitao FS, et al. CPAP and survival in moderate-to-severe obstructive sleep apnoea syndrome and hypoxaemic COPD. Eur Respir J. 2010; 35(1):132-137.

[186] Kushida CA, Littner MR, Hirshkowitz M, et al. Practice parameters for the use of continuous and bilevel positive airway pressure devices to treat adult patients with sleep-related breathing disorders. Sleep, 2006;29:375-80.

[187] Schafer H, Ewig S, Hasper E, et al.. Failure of CPAP therapy in obstructive sleep apnea syndrome: predictive factors and treatment with bilevel positive airway pressure. Respir Med, 1998;92:208-15.

[188] Sanders MH, Kern N.. Obstructive sleep apnea treated by independently adjusted inspiratory and expiratory positive airway pressures via nasal mask. Chest, 1990;98:317-24.

[189] Kakkar RK, Berry RB. Positive airway pressure treatment for obstructive sleep apnea. Chest, 2007;132:1057-72.

[190] Holanda MA, Fortaleza SCB, Alves de Almeida M, et al. Continuous positive airway pressure effects on regional lung aeration in patients with COPD: A high resolution CT scan study. Chest, 2010; 138:305-314. 